\title{
The Effect of the Position of Educational Organizations within the Social Network on Their Collaboration Levels*
}

\author{
Zeynep Uğurlu \\ Department of Education Sciences, Faculty of Education, Sinope University, Turkey \\ *Corresponding Author: zugurlu@sinop.edu.tr
}

Copyright $(2016$ by authors, all rights reserved. Authors agree that this article remains permanently open access under the terms of the Creative Commons Attribution License 4.0 International License

\begin{abstract}
In this research, it has been aimed to determine the opinions of administrators serving in the public education organizations at the central districts of Sinop on inter-organizations collaboration (collaboration levels). The study, in the descriptive survey model, has been carried out by a mixed research approach where qualitative, quantitative and social network analyses have been used collectively. At the qualitative phase of the research, 36 school

coalition and collaboration, the highest achieved collaboration is the collaboration level. In conclusion, meaningful differentiations have been determined between collaboration subjects and levels, depending on the positions of the organizations within the network (central actor, effectiveness level and betweenness condition). Positions within the network have an impact on the collaboration levels of organizations.
\end{abstract} administrators have been interviewed, and then the interview inventory has been subjected to content analysis. In the social network analysis phase of the research, the Collaboration Levels Scale developed by the researcher has been applied to 36 school administrators. The obtained data have been analyzed in the UCINET 6.0 software. The density, structural holes, centrality degrees of the responses of the administrators to the items included in the scale have been calculated and network maps have been generated. In the quantitative phase of the research, whether the positional characteristics of the administrators within the organization and network demonstrated variations depending on variables or not has been analyzed with the Mann-Whitney $U$ and Kruskall Wallis Test, since the distribution was not normal. According to the conclusions reached in the study, 36 education institutions have established a collaboration network of 68 actors, including themselves. From these organizations, 39 are education organizations, while 29 are public, private sector and non-governmental organizations. All education organizations at the provincial center have established a collaboration network. There are no isolated organizations. According to the density analysis, 57\% of the maximum relations that the organizations could achieve among themselves, has been established. Accordingly, the education organizations have both close and distant connections within the collaboration network. According to the research findings, the education organizations at the provincial center display a structure that is very close within themselves - but closed to the outside. While the areas where the collaboration potential could be used the most in proportion are data sharing, financial resources sharing and administrator opinion exchange, the lowest levels have materialized in working on a common project, institutional health and safety. Among the collaboration levels, from the five levels that are networking, cooperation, coordination,
Keywords Educational Organizations, Collaboration, Collaboration Levels, Social Network Analysis

\section{Introduction}

The general purpose of actions conducted in the area of educational system are to meet the expectations of the society from education, provide solutions to educational problems and provide effective and productive use of sources as well. The complexity of social problems and the ambiguity of their limits require the unity of various specialty areas and individuals, parts, units and organizations to work cooperatively as is the case in all other sectors. Therefore, educational organizations collaborate with numerous public and private sector and non-profit organizations in different manners on various issues.

In particular in the age that we live in, a strong tendency towards inter-organizations relationships is observed ([1], [21]). The reasons which impel organizations to collaborate can briefly be listed as lowering the cost of acquiring information, providing the opportunity to benefit from other resources and specialties and experiences, sharing risks and costs, increasing the chance of developing new products and services, protecting and strengthening the prestige and images of organizations, providing access to external markets, providing speed, flexibility and the chance of learning in a corporate level and decreasing the number of people leaving their organizations by increasing the morale of employees ([4], [7], [27], [66], [74]). In the recent years, one of the most important reasons that impel organizations to collaborate with other organizations is the insufficiency of existing organizational structures in solving the problems 
which arise. For these and similar reasons, inter-organizations collaboration relations are becoming more and more wide-spread under different names and manners.

Numerous concepts which mean inter-organizations collaboration make it difficult to define it. In literature, there are many concepts which are used in relation to inter-organization collaboration such as conjunction, coadjuvancy, association, league, cahoot, alliance, unify, merge, coadunation and coexistence. Although collaboration is regarded as an effective protection and prevention strategy, it has been observed that collective efforts and systematic studies which are accepted as collaboration in the real sense are confused with one another [8]. Despite the fact that a great number of different concepts are being used, there are five main characteristics of inter-organizations collaboration according to Gray[39]: (1) Organizations which collaborate are independent of each other. (2) Solutions are presented through constructive efforts which are mutually displayed by protecting the differences. (3) All of the participating organizations participate in the decision making process. (4)There is a common responsibility between all the collaborating organizations. (5) Collaboration is a process which suddenly emerges with the purpose of dealing with the increasing complexity in the organizational environment together with the other organizations. The give a definition, Inter-Organizations Collaboration is a relationship based on the foundations of responsibility, authorization and accountability which are shared with the purpose of acquiring mutual benefit aimed at common objectives between two or more organizations ([87], reported Frey[31]).

\subsection{Levels of Inter-Organizations Collaboration}

Collaboration is classified in many different manners. The most general classification about collaboration is made in terms of the similarities and differences within the social structure. According to this, while the similarities within the structure keep the actors together, the differences cause them to separate. While harmony represents collaboration and solidarity, separations represent the relationship of conflict and struggle[53]. The attitudes of the actors which constitute the social structure affect the type of collaboration. Actors display different collaboration behavior in terms of similar interests and general interests. According to this, two types of collaboration is created: traditional (cooperation) and contractual (collaboration) [49]. In cooperation, the phenomenon of solidarity is higher. Therefore, solidarity and cooperation are at times mixed up. In brief, the relationship between the behavior of collaboration and the interest type defines its borders[49].
Different researchers who conducted studies on the types and levels of collaboration have classified collaboration in various manners in accordance with characteristics such as objective, structure, process ([12], [33], [44]); definition, source, characteristic aspects and sharing of resources [43]; the density of the relationship, flow of communication among the participants and distribution of power, the dimension of the relationship (its proximity or remoteness), risk and award level[50, 51]. There are new concepts such as coexistence and coadunation each passing day in relation to collaboration levels. The classification below is a classification which is widely accepted. The levels and characteristics of collaboration adopted in this study have been summarized in Table 1.

One of the most basic problems in inter-organizations collaboration is the evaluation of collaboration and of course, the identification of the criterion to be used as a basis for evaluation. According to El Ansari and Weiss[28], the evaluation of inter-organizations collaboration is difficult due to the complexity of the actions and the insufficiency of the existing methods of evaluation. In addition, in order to evaluate collaboration, it is not sufficient to display the existence of collaboration; performance criterion to evaluate collaboration need to be created ([31], [44], [88]). Since displaying the levels of inter-organizations collaboration brings a classification with it in terms of the union of organization during the process of collaboration, it can be used as a reference point in the evaluation of the collaboration that has been carried out $[33,34]$.

According to Hanneman[42], social actions are complex processes which are made up of more than one causal process, which embody numerous actors which are active in more than one dimension. In the analysis of these complex and dynamic processes, creating consistent and beneficial theories are solely possible together with the use of expressions / concepts which are general and abstract in a high level and systematically dealing with these. In evaluations which are to be taken as a basis for the evaluation of collaboration, this approach has given birth to the idea of analyzing the structure. There are numerous findings which show that the analysis approach which allows the analysis of the social structure created by the collaboration relationships (connections) rather than actors has various superior characteristics ([10], [20], [32]). Both the network theory and social capital theory focus on the relationships between people or organizations and the effects of their positions within the network structure created by this network of relationships ([29], [37]). In terms of inter-organizations relationships and collaboration, the social capital theory and the network approach can be regarded as a turning point due to the different point of views they present. 
Table 1. Levels of Collaboration

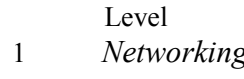

2 Cooperation

Coordination

4

Coalition
Characteristics

Poor connection, low trust, limited sharing of information, flow of communication when required, making independent objectives and actions compatible with each other, keeping power and resources in the organizations, loyalty and accountability towards one's own organization, relatively short relationship time, low risk and low award.

Definition of mutual needs, but guaranteeing working together in terms of carrying out duties with the purpose of preserving the basic identity and acquiring financial gain and interest. All organizations act independent of each other. Information sources are shared. They mutually support each other and share the output. In the process of continuing cooperation, organizations are dependent on each recommendation wise and a formal structure which is not hierarchical and in which certain strategies and tasks are defined is created.

It is aimed at sharing information and resources, identifying roles, establishing frequent communication and taking certain decisions mutually. It is a level of collaboration which is longer in duration and generally lasts until a project or a common objective is realized, in which one of the project partners is relatively more powerful (big partner) depending on the project. In this level in which there are relationships that are totally based on the task, trust based on the task and medium frequency relationships, the channels' structures for this level of communication are used for the tasks. A mutual dependency between organizations is in question. Since the participants control each other in terms of common objectives, the big partner relatively holds more power. It requires tighter connections and a stronger participation in comparison to the lower level.

It is different from the other levels in the sense of sharing ideas and decisions, wide-spread and prioritized communication, all members having one vote in the decision making process, willingness to acquire resources from the existing system and an at least three year commitment of loyalty, participation of all members in the decision making processes, defined roles, formal and written communication, new resources and budget.

It is defined as a structure in which there is involvement in a single system, mutual trust forms firm communication and all decisions are taken by assent. It is defined as the strongest and tightest level of connection. Risk, award, duration and frequency of relationship, communication and trust are of high level. It creates a change in the actions and procedures of the participants. It requires a high level of trust, dialogue and negotiation. Therefore, communication and relationships are firm and intense. Accountability, authorization and shared responsibility are factors which distinguish it from the other levels.

Source: Summarized by making use of sources such as Peterson, 1991; Houge, 1994, Borden \& Perkins, 1998, 1999; Himmelman, 2002; Gajda, 2004; Frey, Lohmeier, Lee \& Tollefson, 2006; Sennet, 2012; Keast \& Mandall, 2007, 2009.

\subsection{Social Capital Theory}

The first theory which drew attention to the fact that social relationships guide economical relationships is the concept of social embeddedness. The social embeddedness argument put forward by [38] reported Granovetter asserts the importance of social links in economical relationships. The assumption that economical actions are embedded in social relationships began to gain importance in organizations and inter-organizations relationships with the contributions of Granovetter[38]. However, the argument of social embeddedness has been criticized on the grounds that it does not present an alternative which can replace the rational actor model [89], the corporate and empirical studies carried out to show that embedded relationships provide benefits to the parties in the exchanges taking place in the markets being insufficient[90] and a possibility of exploitation intend mutual expectations of trust in the embedded relationships [90]. It is possible to say that the social capital and network theories partially bring an explanation corporate gaps arising from the mentioned criticisms and the measurement ambiguities of social embeddedness [76].
Social capital is defined as relational sources which may be useful for development of individuals which are embedded in personal links and within the social organization of the society [91]. According to Gargiulo and Benassi[35], social capital is tangible and abstract benefits acquired through mutual network relationships that are based on friendship and acquaintance. However, the issue of through what kinds of relationships social capital can be acquired has caused social capital theoreticians to suggest different ideas:

1. Strong Links Theory: Traditionalists argue on the social capital theory that close social links allow the formation of social norms and harmony which facilitate trust and common trade relationships between actors[35]. The formation of these strong links can be possible through actions such as long-term interactions between the parties, physically being close and participating in common activities. It has been claimed that close and strong social links provide the parties with advantages such as a high amount of information transmission and easy access to the sources. In summary, 
traditionalists have suggested that the strong and close relationships within arm's length are more effective than weak and remote connections in the formation of social capital ([13], [70], [92]).

2. The Power of Weak Links: Contrary to the first point of view, social capital theoreticians such as Granovetter[38] and Uzzi[90] have claimed that weak and remote connections are more advantageous due to increasing the variety of acquired information and the capacity of providing innovations. They have argued that since weak and remote relationships make it possible to connect with actors in more distant environments, they provide more quality benefits in comparison to the close range relationships.

3. Structural Holes Theory: As a third point of view, Burt[14] has claimed that there is a hybrid structure made up of both the strong and weak connections of the actors within the network structure and that what is important is the positions of actors within the network. According to this theory, as the network grows, it becomes difficult for all the actors to form relationships with each other. As the network grows, the number of actors which do not have any connection with each other will unavoidably increase. Under these conditions, structural holes are formed in the relationship network. These structural holes in turn prevent the flow of information. In such cases, some actors act as bridges between the other actors and fill the structural holes and gain more advantage by controlling the flow of information. According to this point of view, the value of each actor within the network is not the same. The actors either have more or less social capital due to their positions within the networks and the roles they have assumed.

In the social capital theory, an approach arguing that only one of the relationships is more superior can be misleading in the evaluation on what kinds of relationships create social capital. At this point, instead of an expression stating that one is superior to the other, the fact that all three points of views have weak and superior aspects in themselves should be taken into consideration. In fact, Lin [93] has stated that what is determinant in social network structures and characteristics is the actor's objective and that the actor prefers relationships which are related to his objectives. In the interpretation of collected empirical research data in the analysis of these relationships mentioned in the social capital theory, the network theory and the analysis techniques it makes use of have provided an important contribution.

\subsection{Social Network Theory}

The network phenomenon is an abstract concept which is made up of nodes and edges which tie these nodes together [26]. The network concept is a cluster of connections or a network of relationships[68]. In the narrowest sense, the network approach and analysis is a method of numerically and/or graphically mapping the type, direction and intensity of relationships between a group of actors [68]. Network studies have been supplied data from three different sources: mathematical approaches, anthropological and sociometrical approaches and organization analysis studies[54] The social network theory which has been created making use of numerous disciplines is defined both as an organizational substructure and a bundle of methods ( [60], [71]).

According to Gulati [40], the basic assumption of the social network theory is that economical actions are influenced by the social context they are actualized and that similarly actions are influenced by the positional characteristics of the actors which make up the social network. According to Wasserman and Faust[84], the four main foundations of the social network analysis are solidarity (mutual loyalty), connections between the actors, and the influence of the network structure and the continuity of the relationships between the actors. Social networks are created through all social relationship clusters which are possible within a certain context (communication, power, exchange relationships) connecting the actors with each other ([10],[29],[40]). In the network approach, the relationships between the actors are analyzed through unique analysis approaches and interpreted by making use of social capital concepts as well.

The main analyses used in a typical network analysis are measurements such as density, cluster, cliques, network centrality measurements (degree, closeness, betweeness etc.) and structural holes. Although there are numerous analysis techniques used besides these, the analyses used in general in the analysis of a relationship defined between the actors in various dimensions has been summarized below ([6], [10], [20], [41], [55], [68], [72]):

- The three main characteristics which constitute $a$ network are actors (node), relationships between the actors (edge) and the structure formed by the two. All of these form a network and there should be at least two actors. The size of a network depends on the number of actors which constitute it. As the number of actors and relationships increase, the size of the network increases as well and the network gets complex.

- The density of the network shows how much of the maximum relationship which can be established by the actors within the network have been formed. In other words, the ratio of the number of established relationships to the number of relationships which can be established is defined as the density measure of the network and is expressed as \%. As the calculation of network density makes it possible to compare different networks, it also gives clues as to whether the relationships within a specific network structure are strong or weak connections as well. Networks with strong connections show close and strong relationships, whereas networks with weak 
connections show distanced relationships.

- Network centrality measures (degree, closeness, beetweeness centrality) shows the position of the actors within the network. Degree centrality shows how many times the actors within the network connected, or how many times they established relationships with the other actors; or if they have not established relationships, whether they are isolated or not. If there is an actor with a higher degree centrality, it can be stated that this actor is more efficient in comparison to the other actors within the network, has more access to sources and information and thus establishes more relationships with the other actors. Actors with higher degrees and more number of connections are positioned at the center of the network, whereas actors with lower degrees and fewer connections are positioned at the sides of the network. It can be identified that an actor with a lower degree or an actor who cannot establish any relationships is isolated and cannot make use of the opportunities within the network.

- However, this measurement does not always accurately show the importance of the actor. Some actors can reach critical importance by acting as bridges between the others making use of the lack of relationships despite having a lower number of connections. According to this type of analysis which is defined as beetweeness centrality, the actors which act as bridges can create opportunities for themselves and increase their efficiency within the network and their degree of importance can be high. They can make themselves more efficient by filling the structural holes within the network.

There are numerous analyses used in network analysis techniques. These analyses which have been briefly summarized are modellings which have been created by making use of typical mathematics and physics models. They are presented through numerical data and graphics, however they are interpreted in social sciences through theoretical foundations which mostly have been previously explained in the social capital theory.

The social network theory is different from other theories in terms of scientific understanding. The social network theory which has been developed by the contributions of scientists who are in general against the traditional understanding of analysis primarily not being reductionist and not taking linear rationality as the basis attributes the theory a different stand among the other approaches. Secondly, it rejects the assumption that "social behaviors are a sum of individuals' behaviors" in traditional sociology and has brought a useful point of view as to how social connections shape economy and organizations as a result of making the relationships between the actors are area of [29]. Thirdly, through the social network analysis method used in the studies on the theory, focusing on data resulting from the interactions between organizations instead of attempting to understand organizations independent from each other creates a contrast with the dominant research methods in the field and since it does not comply with the rule of the independence of the measurements from each other, it makes the use of standard analysis approaches used in traditional science impossible. That is the main reason why it creates techniques unique to itself in the analysis of relationship data ([68], [76], [102).

\subsection{Social Capital and Network Theories in Organizational Analysis}

In organizational analysis, the usage area of the social network theory is diverse in the interpretation of inter-organizational and inner-organizational collaboration. The first use of network approaches in organizational analysis goes back to experiments in which inter-organizational relationships have been analyzed and which provided a source for the initiation of human relations movement. The social network approach in organizations goes back to the use of socio-metrical techniques developed by Moreno[65] in the Hudson Company. These techniques have been used in experiments conducted during the Hawthorne researches at the Western Electric Company by Rotlishberger and Dickson in the same years as well. In the mentioned researches, the relationships between the employees in organizations and groups have been analyzed. According to Kinduff and Tsai[54], these researches are the roots of social network analysis in organizational studies.

The network approach in organizational analysis to a certain extent removes the insufficiencies of traditional approaches in explaining the complex nature of inter-organizations relationships. Revealing the hidden information of informal structure formed in organizations and allowing the presentation of complex processes in a plain manner facilitates understanding organizations more in-depth in comparison to traditional approaches [20]. The network analysis used in the evaluation of relationships between the people within organizations in the analysis of social capital relationships has been dealt with in terms of the evaluation of organizations' social capital in the organizational dimension. Organizations spend effort to extend their social networks in order to acquire power in their own technical and corporate environments just like people. An organization's social capital can be defined as a series of tangible and abstract sources accumulated by the organization as an actor through its social relationships which allows the organization to reach its objectives[76]. Different views have been put forward in terms of the source of the social capital of organizations. Some researchers state that the social capital of organizations is largely made up of the social capital of the employees of organizations. Some other researchers claim that the social capital of organizations does not solely belong to individuals of the organizations, but that it is as a whole sources created commonly by organizations and their members[57].

Just as individuals' social capital is evaluated in terms of the relationships established by other people, organizations' 
social capital can be evaluated in terms of the relationships established with other organizations and people. In accordance with the closeness, intimacy, trust, spending more time together, participating in common activities and spending time in social environments in interpersonal relationships facilitates establishing relationships and collaborating. In inter-organizations relationships, one method of conceptualizing the concept of closeness is to deal with which organizations collaborate with each other or their degree of working together. According to Thorelli[101], the most significant part of an organization's environment is the organizations around it. According to Van De Ven [82], inter-organizations relationships which depend on mutual collaboration start out as relationships which are not too risky, of low density and do not require a high level of trust and transform into established relationships by time. Social network researches are used in inter-organizational relationships as well besides being used in the evaluation of interpersonal relationships. The studies which have been conducted so far show that data which can be used to evaluate the development of inter-organizations collaboration can easily be collected over the networks [21]. According to Kadushin, Lindholm, Ryan, Brodsky \& Saxe[48] network analysis can provide unique information on the structure of the connections between organizations and thus, can be used during the process of forming collaboration and coordination. According to Cross et al.[21], network analysis can reveal the structures of collaboration and can compare them with effective structures. This approach can be used as a method to fill the gap created by the existing methodologies, with the purpose of analyzing the structure of active relationships of collaboration and to reveal the degree of primary relationships of collaboration.

\subsection{Inter-Organizations Collaboration and Social Network Theory Perspective in Education}

The main purpose of collaboration between schools and between people employed in schools is to develop schools' standards and increase the level of success, allow the sharing of professional knowledge and expertise among teachers, enriching the learning opportunities of students and facilitating the removal of obstacles in learning ([3], [23], [24], [81]). According to Pounder[94], the following questions/problems should be given importance to while discussing the issue of collaboration in the area of education: (1) What is the structure of organization that can increase the performance of collaboration between schools? (2) What carries the primary importance in the period of change required for the creation of collaboration process at schools? (3) What is the cost of collaboration (effort, energy, time, other sources) with other actors (people and organizations)? (4) How should the teachers' studies be structured in terms of working with collaboration? (5) What are the outputs of collaboration for teachers and students? (6) In order to establish common working relationships between educators at schools (administrator, teacher, special educators, consultants and psychologists), how can the differences arising from these groups' occupational roles be removed and how can these be harmonized? (7) What are the effects of collaboration for teachers and learners? The subject of collaboration in the area of collaboration and the studies conducted has generally focused on the dimensions stated here.

According to Taymaz[79], schools' collaboration with their environment can firstly be possible through administrators of education inviting the representatives of related institutions and organizations in their environments to collaborate with their school and creating willingness to collaborate; guiding the views and actions of the groups and leaders in their environment towards the objectives of their school and developing projects to be carried out by the related organizations on environmental problems or supporting the developed activities through education. Due to schools' need to receive the support of their environment, school administrators should increasingly assume more active roles to manage the environment they are in.

In the studies, it is pointed out that collaboration between the employees within the school environment has both positive contributions to students' success and the creation of a positive learning environment and their school development process ([9], [64], [75], [80]). Similarly, collaboration with other people, groups and organization within the school environment facilitates reaching educational objectives.

When collaboration is perceived as an interdisciplinary concept and a problem solving strategy, it is included in almost all problem solving actions. In the study carried out by Jager[47] on 23 schools in East Basildon, it has been determined that there is a wide program of collaboration which also embodies various support programs between educational institutions and health, police and social services, development and monitoring of student performance. According to Slater and Ravid[75], collaboration takes place in various areas such as sharing of information and sources between schools and other organizations, consultation, support, solidarity, activities related to school developmentreforms and sharing of views. In the evaluation carried out by Marra, Peterson and Britsch[62] of the national project on the development of collaboration among girls, it has been stated that collaboration between all social organizations and project partners in the realization of projects can be used as a lever and a collaboration model has been suggested. As it can be seen, schools' collaboration relationships with their environments take place in various subjects and manners. This leads to the relationships of collaboration among schools to be referred to using different concepts.

Atkinson et al.[3] have underlined the variety in the concept used for collaboration relationships of schools. A range of terms are used almost interchangeably to describe working relationships between schools, including: clusters, collaboratives, collegiates, confederations, consortia, federations, networks, partnerships, school families, twinned schools. Hanford et al. ([95] reported by Atkinson \& etc, [3]) have defined the collaboration relationships among schools 
under four levels as networking, coordination, cooperation and collaboration. Lieberman and Grolnick [58] have grouped the main characteristics of the 16 educational reform networks they have researched in the USA under five groups: (1) objective, coming together around an idea, (2) creating collaboration and loyalty, (3) network activities and relationships, (4) leadership and facilitation, (5) resources. Overall, three principal dimensions could be said to underlie all of these classification systems, each dimension ranging from low risk/low benefit potential to high risk/high benefit potential [3]:

1. Organization: How far do organizational structures support the collaborative working?

2. Penetration: How deeply into the fabric of the school does the collaboration penetrate?

3. Joint investment: To what extent do partner organizations share a vision and aspirations for the collaboration?

Another dimension among schools as educational organizations is the success of the established collaboration relationships. Ash[2] in his study including 327 organizations in which he evaluated the collaboration of schools with other organizations, has identified nine underlying factors in the successful and unsuccessful relationships according to the satisfaction levels of the coordinators of the schools which cooperated in the area of education: effectiveness; reconciliation; communication facility; frequency; formality; similarity of the sphere of influence; perception towards collaboration; period of getting to know the organization and resource dependency. According to Packdell's study[69], collaboration in the educational networks made up of state educational organizations in the educational area in Oregon displayed seven categorical characteristics: A shared vision for social change; a strong leadership capacity which creates change; open and candid communication (structuring the relationships between the workers based on trust); workers in whom differences are preserved and united; the suitability of the resources; loyalty and dependencies in the sharing of resources and expansive supportive leadership; consideration of the successive steps in planning, continuity and the existence of a development plan. This study and similar studies are focused on the requirements of successful establishment of collaboration relationships and their sustainability.

In terms of developing collaboration, Gajda[33] suggests firstly that those who will be collaborating to come together and determine the type and level of collaboration and openly define the mutual obligations, identity objectives and goals, identify the flaws in the process through the use of frequent measurement mechanisms and the use of improvement mechanisms and to revise the rules, plans and programs from time to time for sustainability although these need to be determined at the beginning of the process. According to Woodland and Hutton[86], the process of collaboration can be seen as an intertwined network phenomenon created by those who come together around the shared common objectives and goals. This cycle involved the stages of decision making, dialogue, action and evaluation. The continuity of this cycle requires collection of data, planning and implementation of plans which are to be the basis of continuous evaluation. However, difficulties of the complexity in actions and repeated relationship cycles, reaching the identified objectives and acquiring proof of sustainability limit evaluating how efficient collaboration is and developing the process ([8], [28]). Deal, Purinton and Waetjen[96] state that due to the potential of revealing the informal structures in the understanding of dynamic relationships between the actors in schools and the school environment, the social network approach can remove this restriction.

Social network studies in education as in other areas focus on how interpersonal relationship patterns facilitate the flow of relational resources (such as knowledge, expertise, attitudes and friendship) which act as a lever and how accessing the resources is affected. Network perspective does not only present a set of methods for the understanding of the importance of individual behavior, but also the understanding of the dynamics of social processes in education[97]. The increase in the number of concepts unique to social networks more and more in the area of education as well as in other areas has reflected on studies on education too. Studies conducted through numerous social network analysis perspectives which deal with the various dimensions of the relationships between teachers, students, administrators and schools and other organizations have increased in the recent years ([16], [17], [25], [30], [64], [77], [83], [98]). These kinds of studies in which various relationships patterns such as supporting educational reforms, the effect of various network relationships between teachers on performance, the vocational development of teachers and knowledge and information transmission have begun to increase all over the world. However, although studies conducted with the social network perspective are quite limited in number, they are not wide-spread yet in educational studies. Studies in which schools' relationships with other organizations are evaluated with the social network perspective have not been come across. However, collaboration relationships of educational organizations among themselves and with other organizations in Turkey are wide-ranging.

Firstly, the Republic Turkey Ministry of Education which is the primary organization responsible for education carries out educational projects with various organizations abroad. Various projects which involve transnational collaboration relationships such as the European Union, The World Bank and UNICEF are carried out with objectives and areas such as improving the quality of education, improving the management of education, increasing the success of students, education of democracy and human rights, healthy schools and life-long learning. In addition, schools establish continuous and repeated collaboration relationships with the different organizations of society with purposes such as health screening, vaccination campaigns, providing the 
security of institutions, providing equipments, artistic activities and similar reasons. Despite the high number of conditions which necessitate educational organizations to collaborate among themselves and with other organizations, it has been observed that studies on collaboration and levels in educational researches in Turkey are limited. The evaluation of collaboration relationships which are quite complex, repeated and create a high number of relationship pattern through the network perspective and revealing their reasons in-depth through dialogues will facilitate the understanding of inter-organizations collaboration processes in educational organizations in a deeper level. In this light, the purpose of this study is to determine whether the collaboration levels of educational organizations with each other and other organizations are influenced from their positions within the social network.

\section{Purpose}

The general purpose of the study is to determine the effect of the position of educational organizations within the network on their collaboration levels. In accordance with this general purpose, the answers to the following questions have been sought:

1- According to the administrators of educational organizations;

(a) How is the concept of collaboration perceived?

(b) What are the reasons for inter-organizations collaboration?

(c) According to which criteria do they choose the organizations they are going to collaborate with?

(d) What are the organizations with which voluntary and mandatory collaboration is carried out? And why?

(e) What are the barriers of inter-organizations collaboration?

(f) What can be done to improve inter-organizations collaboration?

2- The educational organizations which are located at the city centers collaborate with;

(a) Which schools and organizations?

(b) Which areas and

(c) Which levels?

3- Which educational organizations are more central?

4- Between which educational organizations is the collaboration relationship closer?

5- How are the density levels of the educational organizations within the social network?

6- Which of the educational organizations centers have formed subgroups?

7- Do the collaboration levels of the educational organizations change according to the variables of;

(a) Organization type,

(b) Organization kind,

(c) Physical distance,

(d) School size, (e) Demographic characteristics of administrators (age, gender, duty, education, seniority, administrator seniority, employment duration at the organization?

8- Do the collaboration levels of the educational organizations change according to the social network characteristics?

\section{Method}

\subsection{Research Model}

This study which was done to examine and evaluate the collaboration relationships between educational organizations via the opinions of school administrators is a general descriptive survey research. General descriptive survey research model is a research approach which is designed to report a past or present situation as much objectively as it is[5].

The study, in the descriptive survey model, has been carried out by a mixed research approach where qualitative, quantitative and social network analyses have been used collectively. Mixed researches are defined as researches in which researchers use qualitative and quantitative approaches together in a single study [18]. In mixed research, the researcher collects and analyzes both the qualitative and quantitative data in a persuasive and meticulous manner in accordance with the research questions. The researcher integrates and interconnects two types of data at the same time, by either placing one inside the other or successively building one over the other and thus unite them [19].

The qualitative approach in the interpretation of data collected through the factors at the root of collaboration relationships and other research approaches has served as a catalyst in this study. The social network approach used in the study is based on the communication and interaction between the actors [59], [72]. In the narrowest sense, social network analysis is a numerically and/or graphically mapping method of the type, direction and density of the relationships between a group of actors[68]. According to Freeman[32], the following characteristics are seen in all modern social network analysis samples: (1) Social network analysis justifies intuitions on the structural links which connect social actors with each other. (2) This empirical data is systematically collected and is controlled. (3) This data is presented as graphics. (4) In these calculations, mathematical models are relied on. Lastly, the quantitative research approach used in the study has been included in the study due to its tendency to form causal relationships between concepts. In the study, quantitative research techniques have been made use of in the researching of the relationships between the levels of collaboration and the different variables.

The study is a case study carried out at the Sinop city center as well. Case studies are the research method which studies a current phenomenon within the framework of real life, in which the borders between the phenomenon and the environment it is in are not clear cut and are used in instances where there are more than one proof or data source[36]. 


\subsection{Study Group}

Participants of this research is the school administrators and administrators who are working in the all educational levels in public schools and other public educational organizations in the city center of Sinop (a county in western Turkey) in 2012-2013 academic year. The demographic characteristics of the study group have been presented in Table 2.

As shown in the Table 2., 33 (92,3\% ) of the participants are male and $3(7,7 \%)$ of them are woman. There are 24
$(66,7 \%)$ of the participants school principals, $6(16,7 \%)$ of the participants manager (affiliated educational public organizations's managers) and $6(16,7 \%)$ of the participants deputy principals. $4 \quad(11,1 \%)$ of the administrators have administrative experiences within the interval of 0 to 5 years; $7(19,4 \%)$ have 11 to 15 years of administrative experience; $10(27,8 \%)$ have 11 to 15 years of administrative experience; $11(30,6 \%)$ of them 21 years and more. Only one administrator representing each organization has been reached (Table 2).

Table 2. Demographic Characteristics of Participants

\begin{tabular}{|c|c|c|c|}
\hline Variable & Subvariables & $\mathbf{N}$ & $\%$ \\
\hline \multirow{2}{*}{ Sex } & Female & 3 & 7,7 \\
\hline & Male & 33 & 92,3 \\
\hline \multirow{4}{*}{ Age } & $25-34$ & 1 & 2,8 \\
\hline & $35-44$ & 11 & 30,6 \\
\hline & $45-54$ & 15 & 41,7 \\
\hline & $55-64$ & 9 & 25 \\
\hline \multirow{3}{*}{ Education } & College & 10 & 27,8 \\
\hline & Graduate & 25 & 69,4 \\
\hline & Post-graduate & 1 & 2,8 \\
\hline \multirow[t]{3}{*}{ Administrative Position } & Manager & 6 & 16,7 \\
\hline & Principal & 24 & 66,7 \\
\hline & Deputy Principal & 6 & 16,7 \\
\hline \multirow[t]{4}{*}{ Experience } & $0-5$ years & 1 & 2,8 \\
\hline & $11-15$ years & 4 & 11,1 \\
\hline & $16-20$ years & 8 & 22,2 \\
\hline & 21 years and over & 23 & 63,9 \\
\hline \multirow[t]{5}{*}{ Administrative Experience } & $0-5$ years & 4 & 11,1 \\
\hline & $6-10$ years & 4 & 11,1 \\
\hline & $11-15$ years & 10 & 27,8 \\
\hline & $16-20$ years & 7 & 19,4 \\
\hline & 21 years and over & 11 & 30,6 \\
\hline \multirow[t]{5}{*}{ Duration at the Organization } & 1 year or less & 10 & 27,8 \\
\hline & 2 years & 6 & 16,7 \\
\hline & 3 years & 13 & 36,1 \\
\hline & 4-10 years & 4 & 11,1 \\
\hline & More than 10 years & 3 & 8,3 \\
\hline Duration of Administrative & 1 year or less & 11 & 30,6 \\
\hline \multirow[t]{2}{*}{ Position at the Organization } & 2 years & 6 & 16,7 \\
\hline & 3 years & 13 & 36,1 \\
\hline
\end{tabular}


In the study, categories and subcategories have been formed with the purpose of making comparisons of inter-organizations collaboration levels located within the educational network in the study. The categories formed in line with the objectives of the study are: organization kind, type, size and physical distance (geographical location):

1. Organization kind: This category has been separated into three subcategories as (a) elementary schools (1 st-8th grades), (b) secondary education schools (9th-12th grades) and (c) affiliated public organizations. Affiliated public organizations are Teacher Social Centre, Guidance Research Center, Science and Art Center, Vocational Training Center, Public Education Center, Special Education Center. There is one of each of these organizations at the city center.

2. Organization type: In this category, there are two subcategories: (a) schools and (b) affiliated public organizations.

3. Organization size: In this category, the group school sizes in accordance with the current students have been accepted as (a) 0-99 students, small schools (SS), (b) 100- 399 students, medium sized schools (MSS) and (c) 400 students and over, big schools (BS).

4. Physical distance: This category has been separated into three subcategories in accordance with the physical distances of the educational organizations as: (a) center, (b) immediate vicinity and (c) central village. Physical distance is an important criterion in terms of the structural comparison of the network characteristics of the actors among themselves (Scott, 1999). People who are close to each other creating opportunities which raise the level of communication and cooperation requires the same factor to be taken into consideration in the area of inter-organizational relationships as well[37].
In the study, the distribution of schools and affiliated organizations which constitute the educational organizations network at Sinop city center in accordance with organization kind, type, size and physical distance have been presented in Table 3.

As shown in the Table 3, there are 39 educational organizations located at Sinop city center. $22(56,4 \%)$ of the organizations are primary schools; $11(28,2 \%)$ of the organizations are secondary schools and $11(28,2 \%)$ of the organizations are affiliated public organizations. Primary schools constitute the highest number of schools. $33(84,6 \%)$ of the organizations are schools; $6(15,4 \%)$ of the organizations are affiliated public organizations. $21(53,8 \%)$ of the organizations are at the city center; $9(23,1 \%)$ of the organizations are at the affinity and $9(23,1 \%)$ of the organizations are at the central village. $17(43.6 \%)$ of the organizations are medium size school; $11(28,2 \%)$ of the organizations are small and big schools.

\subsubsection{Developing the Data Gathering Instruments}

In order to collect data specific to the quantitative, qualitative and social network analysis, two data collection tools have been designed as Levels of Collaboration Interview Forms (LCIF) and Levels of Collaboration Scale (LCS). With the purpose of collecting data in the qualitative stage of the study, a semi-structured interview form has been developed. In the LCIF preparation stage, firstly the related body of literature has been reviewed. The prepared form draft was then sent for the expert opinion along with the LCS. After the expert opinion was received, corrections were made and the pre-implementation of both instruments was carried out in the same period and in the same group. In the pre-implementations, the clarity of the questions in the interview form was reviewed once again, the repeated questions were taken out and expressions were shortened.

Table 3. Variable Values in Numbers (N) and Percentages (\%) Related to the Organizations at Sinop City Center in the Research

\begin{tabular}{|c|c|c|c|}
\hline Variable & Subvariebles & $\mathbf{N}$ & $\%$ \\
\hline \multirow{3}{*}{ Kind } & Primary school & 22 & 56,4 \\
\hline & Secondary school & 11 & 28,2 \\
\hline & Affiliated public organizations & 6 & 15,4 \\
\hline \multirow{2}{*}{ Type } & School & 33 & 84,6 \\
\hline & Affiliated public organizations & 6 & 15,4 \\
\hline \multirow{3}{*}{ Physical distance } & Center & 21 & 53,8 \\
\hline & Affinity & 9 & 23,1 \\
\hline & Central Village & 9 & 23,1 \\
\hline \multirow{3}{*}{ Size } & 99 and less (SS) & 11 & 28,2 \\
\hline & 100-399 (MSS) & 17 & 43,6 \\
\hline & 400 and over (BS) & 11 & 28,2 \\
\hline TOTAL & & 39 & 100,0 \\
\hline
\end{tabular}

Source: Sinop Provincial Directorate for National Education Department of Statistics (2012) 
In the preparation of the LCS used with the purpose of collecting data in the study's quantitative and social network analysis dimensions, firstly the body of literature was reviewed and measurement tools and criterion used in the identification of collaboration levels have been researched. As stated in the related body of literature, there are various classifications related to collaboration levels. In this study, Frey, Lohmeier, Lee \& Tollefson's[31] scale carrying the same name has been made use of with their permission. LCS has been developed by the Midwest Education Region School Program Evaluation and Research Team with the purpose of measuring the progress within the scope of Safe Schools, Healthy Students Project carried out since 1999 with the collaboration of USA Ministries of Justice, Health and Social Services and Education and to evaluate the development of inter-organizations collaboration receiving grant support.

In the scale, there are five collaboration levels and characteristics. These levels have been graded from the lowest level to the highest level as (1) Networking (2) Cooperation (3) Coordination (4) Coalition and (5) Collaboration (Levels of Collaboration Scale, Directives):

1. Networking: Superficially defined roles, low communication; being aware of (other) institution/institutions and all decisions being taken independently.

2. Cooperation: Providing each other with information; more or less defined roles; formal communication and all decisions being taken independently.

3. Coordination: Sharing of information and resources; defined roles; frequent communication and taking some common decision together.

4. Coalition: Sharing of ideas and resources; frequent and prioritized communication; each member having a role in the decision taken.

5. Collaboration: A relationship based on the foundations of shared responsibility, authority and accountability with the purpose of acquiring mutual gains on the common objectives between two or more actors. The members are included in a single system. Mutual trust creates frequent communication. An agreement is reached in all the decisions taken.

Each collaboration level in the scale has been graded in accordance with its position in the order. In order to determine that some actors do not have interaction with the other actors, the option " 0 " (zero) has also been added to the scale. During the application of the scale, the subjects have been asked how much they have collaborated with their partners after each level has been defined. The answer option range between 0 and 5 and while " 0 " indicates no collaboration, "5" indicated the highest level of collaboration. Data collected with the scale were added quantitatively and the perceived average level of collaboration has been determined.

The validity and reliability of the scale used by Frey et al.[31] has been carried out by comparing the results of the four evaluations done between 2002-2005. With the purpose of eliminating the reservation that the scale can be used only as a local evaluation scale, the obtained results have been found to be consistent. The perceived average collaboration in the evaluations carried out at the beginning and end of the years has been determined to be $.85(\mathrm{r}=.85 ; \mathrm{p}<.05), .87$ $(\mathrm{r}=.87 ; \mathrm{p}<.09), .81(\mathrm{r}=.81 ; \mathrm{p}<.09)$ and $.85(\mathrm{r}=.85 ; \mathrm{p}<.08)$ successively in accordance with the test-retest correlation values and reliability levels. According to the researchers, it has been determined that reliability is high in the evaluations carried out for the small samples of the scale $(\mathrm{N}=10)$. In addition, it has been suggested to support the scale with qualitative studies which put forward the dynamics of collaboration.

In the study, the scale developed by Frey et al.[31] has been made use of with their permission. In the classification related to the collaboration levels, the five level classifications in the scale have been adopted as it is. However, some additions have been made to the scale in accordance with the objectives of this study. In the original scale, there is not a section related to the collection of demographic data. In addition, the name generator method has been used in the scale[72]. In this method, the names of the organizations are written directly by the participant. In addition, it does not allow collecting data to determine in which areas collaboration has been carried out and for how many times. Since it is necessary to collect such data to be able to answer the study questions in the developed scale, a personal information form and columns on whether the collaboration is voluntary or obligatory, the collaboration areas and the number of collaboration have been added to the scale. Additionally, the definitions on the levels of collaboration have been shortened and changed into expression of attitude. The developed LCS consists of a directives page and four parts.

Afterwards, the draft scale was presented to the expert views of Education Management and Supervision, Public Administration, Informatics, Statistics and Social Network Research academicians. In line with the suggestions made by the experts, the draft scale which was reformulated was applied in a pilot scheme in a medium sized district of the city where the actual application was carried out. The pre-test and post-test applications have been performed and the reliability (consistency) analyses have been carried out. The pre-test was carried out on 15-17 August, 2012 and the post-test was carried at on 3-6 September, 2012. The time period between the pre-test and the post-test should be long enough not to allow the answers given in the first application to be remembered, but at the same time short enough not to allow certain changes to take place. It is stated that the application in practice should be carried out with a three week interval[78].

Data obtained through the applications of the scale (pre-test and post-test) has been entered into the UCINET software program and analyzed. In the pre-application validity and reliability analyses of the scale used in the study, network centralization evaluations which is one of the analysis techniques unique to social network analysis has 
been used and the two applications have been compared with the UCINET social network analysis. Through the comparison of pre-test and post-test application data matrix and the comparison of network structures allow a comparison to be made on whether the measurement device gives consistent results[68]. In case the two applications are carried out after long intervals, while this analysis is used to determine the evolutionary change which takes place in the network structure ([21], [31]), the applications carried out with short intervals show the consistency in the relationships and evaluation techniques for relationships or the devices. The social network analysis evaluation techniques which can be used in the comparison of networks are achieved in the simplest manner through various network centralization degree analyses such as degree, density and beetweeness which are used to compare the characteristics of the network structure[10]. According to the normalized (transformed into $0-1$ values) and non-normalized network centralization evaluations in line with this, the difference between the two applications was determined to be less than .1. The pre-application evaluations of the district where the pre-application was carried out have been presented in Table 4.

Table 4. Network Centralization and Density in the Pre-application

\begin{tabular}{|c|c|c|c|c|c|c|}
\hline & \multicolumn{4}{|c|}{ Network centralization } & \multicolumn{2}{|l|}{ Density } \\
\hline & \multicolumn{2}{|c|}{ Normalized } & \multicolumn{2}{|c|}{ Non-normalized } & \multirow[b]{2}{*}{ Density } & \multirow[b]{2}{*}{ ss } \\
\hline & Out-degree & In-degree & Out-degree & In-degree & & \\
\hline $\begin{array}{l}\text { Pre } \\
\text {-test }\end{array}$ & 19.340 & 45.82 & 32.063 & 0.174 & 0.3222 & 0.9659 \\
\hline $\begin{array}{l}\text { Post } \\
\text {-test }\end{array}$ & 20.799 & 45.104 & 31.952 & 0.174 & 0.3350 & 0.9812 \\
\hline
\end{tabular}

As shown in the Table 4, the difference between the pre-test and post-test is very small. In the pre-test application, while the network density (the ratio of established relationships in accordance with the maximum possible relationships) was determined to be $32 \%$, this ratio has been $34 \%$ in the post-test. While the number of actors (network size 25) did not increase, the number of connections (the number of collaboration) displaying an increase shows that there are new collaboration carried out with some of the same actors within the network in the post-test, this number was not very high. As a result, since it was concluded that the LCS is consistent due to revealing the network relationships and the differences between the two applications carried out with short intervals being small, it has been interpreted as valid and reliable.

\subsubsection{Data Gathering and Analysis of the Data}

The study reveals public educational organizations' network relationships and their levels in Sinop city central district and analyzes the relationship between their positions within the social network and their collaboration levels. With the purpose of revealing and analyzing the network relationships through the managers, principals and deputy principals of these organizations, samples unique to social network studies have not been taken and a complete count has been performed[59]. The data of the study has been collected by the researcher through the face to face interview technique using the LCS and LCIF. In revealing the collaboration network relationships, methods such as focus group interviews, surveys and analysis of written documents can be made use of[72]. It is apparent that the administrators are the people whose collaboration relationships get most affected by psychological and social processes and use their social relationships for the benefit of their own organizations. Gargiulo and Benassi[35] state that administrators do not only bring the skills and experiences they acquire as a result of years of training to the organizations they work in, but also the assets they acquire through their social relationships. Therefore, when it is also taken into consideration that social relationships have a facilitating aspect in terms of economical relationships, one of the best ways of revealing the network of inter-organizations collaboration relationships is to interview the administrators who establish and manage these relationships on behalf of their organizations. In the study, an interview has been conducted with only one administrator from each organizations has been interviewed in this respect. The permissions to apply the data collection tool have been received from the Sinop Provincial Directorate for National Education. There are 39 educational organizations located at Sinop city center. 36 (92\%) of the educational organizations managers (managers, principals, deputy principals) has been supported this study.

The qualitative interviews of the study have been carried out with the semi-structured interview technique and these interviews have been recorded with a tape recorder. The voice recording has been transformed into texts and the interviews documents have been obtained. These documents were then subject to descriptive and content analysis. The results obtained from the analyses carried out have been compared[63]. In the coding carried out by two independent research specialists other than the researcher, the reliability degree has been determined as $88 \%$ by the first expert and $85 \%$ by the second expert. In addition, sample statements from interview documents have been given place to at times in the research report and the views of the participants have been depicted. After these stages, data analysis has been completed and the findings in the qualitative part of the study have been reached.

In the analysis of social network analysis data, data collected through the LCS have been coded; data matrixes have been created and analyzed with the UCINET 6.0 [11] software used in line with the social network analysis studies. Besides descriptive statistics such as the frequency in the analysis of the quantitative data of the study and \%, due to the number of actors in the groups in relational analyses being low $(\mathrm{n}<30)$ and scores not displaying a normal distribution, non-parametric statistical techniques have been made use of. In the paired comparisons, the Mann-Whitney $\mathrm{U}$ Test as the equivalent of the t-test and in the triple comparisons, the Kruskal Wallis H Test has been used in the non-parametric techniques. In the study, SPSS 13.00 software has been used in the analysis of data collected in 
this group. After the analyses, the following findings have been obtained in the study.

\section{Findings}

In this section, data relevant findings reached in this study is presented. In the study which aimed at determining the collaboration relationships between the educational organizations at the city center, the findings have been grouped and explained in line with the sub-objectives of the study.

\subsection{Qualitative Findings Related to the Processes of Inter-Organizations Collaboration}

1. Definition of the concept of inter-organizations collaboration: According to the findings of the study, 32 out of 36 managers who participated in the study have defined the concept of inter-organizations collaboration as common interest, gaining favors, unity-common action; 17 as facilitation; 21 as sharing resources and 18 as sharing of information by underlining these points. Some sample statements used by the participants of the study on inter-organizations collaboration concept are as follows: "Collaboration means being a unity, gaining power and being successful" [kur5]. "We can use the concept of collaboration in the sense of sharing information and working together" [kur9].

2. Reasons for collaborating with other organizations: According to the findings of the study, 26 out of 36 managers sharing experiences; 24 as providing financial resources; 21 as efficient use of resources; 15 as supporting the development of the personnel; 15 as sharing knowledge; 15 as union of forces in problem solving ; 14 as supporting the development of students; 12 as increasing productivity; 7 as increasing motivation ; 6 as providing expert support; 6 as facilitating the work to be done. Administrators collaborate the most to share experiences. Some of the sample statements related to the participants of the study to cooperate collaborate with the other organizations. "Other organizations contribute to our organization. For instance, the environmental planning of the school has been carried out in collaboration with the Ministry of Forestry" [kur1].

3. Selection criteria for inter-organizations collaboration: According to the findings of the study, 32 out of 36 managers who participated in the study have facilities of the organization; 32 as the attitude of the administrator; 30 as communication; 28 as expert competence; 22 as physical proximity; 17 as harmony; 15 as familiarity. The attitude of the administrators has been explained as, “...... it is not sufficient for the organization to have specific facilities; an attitude in terms of sharing and making others benefit from these facilities is necessary" [kur11]. Therefore, the existence of resources organizations can share allows them to be preferred in terms of collaboration. Administrators' characteristics such as being close to collaboration, having positive views on collaboration and communication shows that social relationships of collaboration are influenced by its main characteristics such as communication, trust and collaboration culture.

4. Obligatory and voluntary collaboration: Collaboration sometimes takes place among public organizations not with the organizations that they choose, but carrying out the pre-programmed activities, instructions and directives. In the study, the collaboration ordered from the higher authorities has been evaluated as obligatory collaboration, while the organizations' collaboration with the organizations of its own choice has been evaluated as voluntary collaboration [85]. According to the educational administrators who participated in the study, it is more appropriate for the ordered collaboration to be referred to as fulfilling duties rather than the concept of obligatory collaboration: "Besides being a school, we are firstly a public organization. It is essential that the duties given by the higher organizations are carried out..." [kur9]. In the study, numerous views have been stated in which the collaboration ordered by the higher organization has been perceived within the concept of duty (kur19, kur28, kur37, kur39). The participants have stated that these duties informed through official correspondence are still being carried out voluntarily. It has been observed in general that the hierarchical level of the organization to be cooperated with is determinant in the perception of volunteering and obligation. A majority of the participants $(n=22)$ have stated that they carry out obligatory collaboration with the higher organizations and both voluntary and obligatory collaboration with the equivalent organizations. As for the question how voluntary or obligatory collaboration influences the quality of work, 18 of the participants have stated that voluntary collaboration is more effective. "...Of course, collaboration is much more effective when it is voluntary rather than obligatory. When people collaborate voluntarily, there are less problems and they go into the process knowing this. However, it is not always necessary to volunteer for certain areas to be collaborated on. Even if you do not volunteer for it, you need to carry the task out in the best manner. Therefore, it does not affect the outcome of the task much. Public work is carried out under all conditions." [kur19]. 


\subsection{Findings Related to the Subject of Inter-Organizations Collaboration}

In the study, it has been determined that educational organizations have a wide range of collaboration relationships with the other organizations. The subject collaborate with other organizations have been presented in Table 5 .

Table 5. Subject of Inter-Organizations Collaboration

\begin{tabular}{lcc}
\hline Subject of Collaboration & N & $\%$ \\
\hline Sharing information & 6378 & 31 \\
Consulting among administrators & 5428 & 25 \\
Sharing financial resources & 4291 & 21 \\
Seminars-courses & 1208 & 5 \\
Sharing buildings-places & 859 & 4 \\
Social activities & 852 & 4 \\
Personnel support & 734 & 4 \\
Organization safety & 457 & 2 \\
Organization health & 345 & 2 \\
Joint projects & 154 & 1 \\
TOTAL & 20706 & 100 \\
\hline
\end{tabular}

According to LCIF data collected from the 36 educational administrators who participated in the study, the educational organizations at the city center have carried out a total of 20706 collaboration work in 2012-2013 period. As it can be seen in Table 5, educational organizations have collaborated most on sharing information $(\mathrm{N}=6378)$ and the least on working on joint projects $(\mathrm{N}=154)$.

Between which organizations collaboration has reciprocally taken place as one of the sub-objectives of the study has been analyzed and determined through the social network analysis techniques. According to LCS data, the social network analysis findings of the study, sharing information have been presented in Figure 1.

As shown in the Figure 1, according to the LCS findings of the study, 452 connections have been identified among the 60 actors within the sharing information collaboration network. It has been determined that the $99 \%$ of the maximum connection possible in the density analysis made for the network $(D=0,99) .8$ of the organizations have not sharing information in the educational areas (Isolation $=8$ ). According to the findings of the study, kur10 has been identified as the organization with the most connections with the other actors (Degree $=46$ ) in the sharing information subjects. Kur10 has been determined as the actor with the highest values of betweeness $($ Betw. $=273,135)$, closeness $($ Clo. $=52,500)$ and eigenvalue $($ Eigv. $=0,285)$. Also kur27 and kur37 has been identified as the organization with the most connections with the other actors (Table 6).

Table 6. Key Players of Sharing Information Network

\begin{tabular}{ccccc}
\hline & Degree & Beetweeness & Closeness & Eigenvector \\
\hline Kur10 & 46 & 273,135 & 52,500 & 0,285 \\
Kur27 & 15 & 216,815 & 48,000 & 0,245 \\
Kur37 & 15 & 172,828 & 35,833 & 0,111 \\
\hline
\end{tabular}

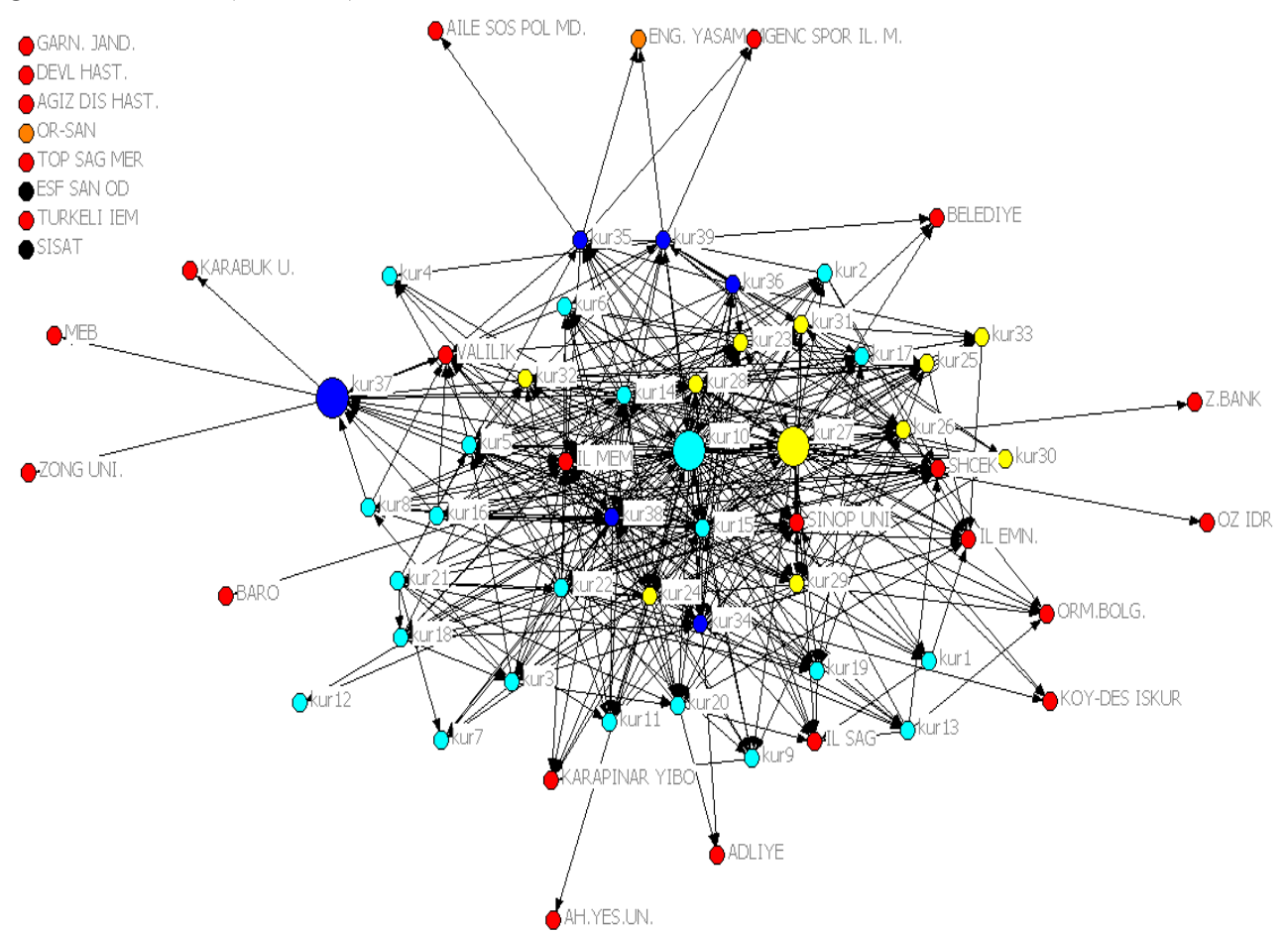

Figure 1. Sharing Information Collaboration Networks. Figure Key: Boxes: actors (organizations) Lines: sharing information collaboration relationships Red boxes: non-educational public organizations Blue boxes: affiliated educational public organizations Yellow boxes: secondary schools Turquoise boxes: primary schools. Big actors: key players. 


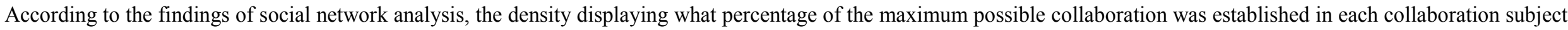

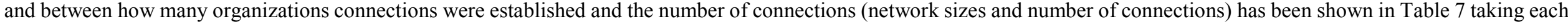
of the subjects into consideration.

Table 7. Summary Table: Inter-organizations Collaboration Subjects in Terms of Social Network Structural Characteristics and Various Variables.

\begin{tabular}{|c|c|c|c|c|c|c|c|c|c|}
\hline Subject & $\begin{array}{l}\text { Network } \\
\text { size }\end{array}$ & Isolated & Ties & $\begin{array}{l}\text { Density } \\
\text { Avg.Value }\end{array}$ & $s s$ & $\begin{array}{l}\text { Density } \\
\%\end{array}$ & $\begin{array}{l}\text { Most } \\
\text { Closest } \\
\text { Actors }\end{array}$ & Key players & Significant Difference \\
\hline $\begin{array}{l}\text { Sharing buildings- } \\
\text { places }\end{array}$ & 52 & 16 & 129 & 0.189 & 12.632 & 19 & $35,10,41$ & $35,10,23$ & $\begin{array}{l}\text { Kind: Between primary schools and affiliated public organizations. } \\
\text { On a higher level in affiliated public } \\
\text { organizations compared to primary schools. } \\
\text { Physical distance: Between city center and village. } \\
\text { On a higher level in city center compared to village. } \\
\text { Type: Between schools and affiliated public organizations. } \\
\text { On a higher level in affiliated public organizations. }\end{array}$ \\
\hline Joint projects & 42 & 26 & 59 & 0.034 & 0.385 & 0.34 & $15,19,41$ & $10,41,28$ & --- \\
\hline Social activities & 47 & 21 & 125 & 0,187 & 2,499 & 19 & $10,28,41$ & $10,41,28$ & --- \\
\hline Personnel support & 49 & 19 & 124 & 0,161 & 3,477 & 16 & $41,37,29$ & $6,24,41$ & --- \\
\hline $\begin{array}{l}\text { Sharing financial } \\
\text { resources }\end{array}$ & 49 & 19 & 96 & 0,942 & 12,173 & 94 & $34,41,29$ & $34,37,41$ & $\begin{array}{l}\text { Experience: Between those who have been employed for } 15 \text { years } \\
\text { and less and } 21 \text { years and more. On a higher level in } \\
21 \text { years and more. }\end{array}$ \\
\hline
\end{tabular}

\begin{tabular}{|c|c|c|c|c|c|c|c|c|c|}
\hline Organization safety & 37 & 31 & 43 & 0,100 & 2,927 & 10 & $41,34,10$ & $5,41,46$ & --- \\
\hline Organization health & 36 & 32 & 34 & 0,076 & 1,888 & 0,76 & $34,41,10$ & $15,41,43$ & --- \\
\hline Sharing information & 60 & 8 & 452 & 0,99 & 10,215 & 99 & $15,10,38$ & $10,27,37$ & --- \\
\hline Seminars-courses & 55 & 13 & 179 & 0,265 & 2,443 & 27 & $35,10,38$ & $10,35,38$ & $\begin{array}{l}\text { Type: Between schools and affiliated public organizations. } \\
\text { On a higher level in affiliated public organizations. }\end{array}$ \\
\hline $\begin{array}{ll}\begin{array}{l}\text { Consulting } \\
\text { administrators }\end{array} & \text { among }\end{array}$ & 58 & 18 & 425 & 0,93 & 10,897 & 93 & $10,35,27$ & $10,27,35$ & --- \\
\hline
\end{tabular}

Total Actor: 68

Actor Numbers: kur1-22: Primary Schools

kur23-33: Secondary Schools

kur34-39: Affiliated public organizations kur41: Provincial Directorate for National Education

kur43: Provincial Directorate of Health

kur46: Provincial Directorate of Security 
As shown in the Table 7., in each of the ten different collaboration subjects, the number of actors (network size), the number of collaboration and their density has been determined to be different. It is understood that the collaboration relationships vary in accordance with the subject collaborated on. In terms of network sizes (the number of actors collaborated with), the most collaboration has been carried out in the subject of sharing information. The least number of actor participation has taken place in the subject of organization health. The number of isolated actors vary in accordance with the subject collaborated on. The least isolated actors have been identified in the subject of sharing information. The most participated collaboration (network size) has taken place in the subject of sharing information (network size $=60$ ). Only 8 organizations have been identified which did not collaborate in this subject. The least participated subject has taken place in the subject of organization and employee health services (isolated=32). According to the density measurements which display the most usage of the possible collaboration capacity, the most collaboration capacity has been used in the subjects of sharing information (Density=0.99), sharing financial resources (Density $=0.94)$ and consulting among administrators (Density=0.93). According to this, the maximum possible collaboration has taken place as $99 \%$ in sharing information, $94 \%$ in sharing financial resources and $93 \%$ in consulting among administrators. The least level of capacity use has taken place in joint projects (Density $=0.034$ ) and organization health (Density $=0.076$ ).

According to the findings of the study, the organizations which assume a key role within the network for each collaboration subject vary. For instance, kur10, kur23 and kur35 have been identified as key actors for the whole collaboration network in the subject of sharing building-place (key players: 10, 23, 35; non-cohesion measure $=0.910$ ). Kur10 and kur35 are also organizations which are closest to each other; (organizations which collaborate the most among themselves). In addition, kur23 is a secondary school located at the city center and opens its gymnasium to other organizations. As it can be seen, organizations which collaborate with other organizations in the subject of sharing building-place within the educational collaboration network are in a more advantageous position due to the physical facilities they have. Their physical facilities allow other organizations to collaborate more with them. Similarly, in line with the study questions, the key actors have been identified for each collaboration subject within the network.

In the study, it has been analyzed whether the collaboration subjects display a significant difference in accordance with the demographic characteristics of the administrators (age, education, duty, experience, administrative experience, duration of employment at the organization, duration of administrative position at the organization) and organizational characteristics (kind, type, size and physical distance). According to the Kruskal Wallis and Mann-Whitney U Test results of the collaboration scores of the administrators of educational organizations who have participated in the study, a significant difference has been observed in collaboration in the subject of "sharing financial resources" in terms of only "experience" among the demographic characteristics of the administrators (Table 8).

As shown in the Table 8., there is a significant difference in the experience of the administrators between 15 years and less and 15-20 years. $\chi^{2}(\mathrm{sd}=2, \mathrm{n}=36)=7,415, \mathrm{p}<.05$. According to this finding, it has been determined that educational administrators with experience of 16-20 years have shared for financial resources in comparison to educational administrators with experience of 15 years and less. Other than this, a significant difference has not been observed in the administrators' collaboration according to the administrators' demographic characteristics in terms of the ten different collaboration subjects. In the study, significant differences have been observed only in the collaboration subjects of sharing buildings-places and seminars-courses and personnel training support in the analyses of the collaboration subjects according to the characteristics of the organizations (kind, type, size, physical distance) (Table 9).

Table 8. Differences among the Experience of Administrators about the Sharing Financial Resources

\begin{tabular}{cccccccc}
\hline Variable & Group & $\mathrm{n}$ & $\begin{array}{c}\text { Average of } \\
\text { Squares }\end{array}$ & $\mathrm{sd}$ & $\chi^{2}$ & $p$ & $\begin{array}{c}\text { Significant } \\
\text { Difference }\end{array}$ \\
\hline \multirow{3}{*}{ Experience } & 15 year and less & 5 & 7,00 & 2 & 7,415 & 0,025 & $1-2$ \\
& 16-20 years & 8 & 22,50 & & & & \\
& 21 years and more & 23 & 19,61 & & & & \\
\hline
\end{tabular}

Table 9. Differences among the Type of Organizations about the Sharing Building-Places and Seminars-Courses and Personnel Training Support.

\begin{tabular}{ccccccc}
\hline Variable & Group & $\mathrm{n}$ & $\begin{array}{c}\text { Average of } \\
\text { Squares }\end{array}$ & $\mathrm{U}$ & $p$ & $\begin{array}{c}\text { Significant } \\
\text { Difference }\end{array}$ \\
\hline Sharing & Schools & 33 & 18,52 & 50,000 & 0,050 & $1-2$ \\
$\begin{array}{c}\text { Building and } \\
\text { Places }\end{array}$ & Affiliated Pub.Org & 6 & 28,17 & & & \\
\hline Seminars- & Schools & 33 & 18,30 & 43,000 & 0,027 & $1-2$ \\
Courses and & Affiliated Pub.Org & 6 & 29,33 & & & \\
Pers. Tra. & & & & & & \\
Support & & & & & & \\
\hline
\end{tabular}


As shown in the Table 9, the analyses results show that there is a significant difference between schools and affiliated institutions in terms of the collaboration of educational organizations in the subject of sharing buildings-places $(\mathrm{U}=50.000, \mathrm{p}<.05)$. When the mean averages of the participants are taken into consideration, it has been observed that the highest number of sharing buildings-places has been carried out by affiliated organizations. Similarly, a significant differences has also been found between schools and affiliated organizations in terms of collaboration in the subject of seminars-courses personnel training support $(\mathrm{U}=43,000, \mathrm{p}<.05)$. This finding can be interpreted as affiliated public organizations such as Public Education Center, Guidance Research Center and Science and Art Center carry out more collaboration activities due to their objectives and the duties they assume (such as expert personnel, providing places, etc.). This aspect makes them significantly different from schools. The findings of the study have shown that collaboration in the subject of sharing buildings-places displays a significant difference according to organization kind and physical distance sub-categories (Table 10).

As shown in the Table 10, the analyses results show that collaboration in the subject of sharing buildings-places displays a significant change between primary schools and affiliated public organizations $\chi^{2}(\mathrm{sd}=2, \mathrm{n}=39)=6,193$, $\mathrm{p}<.05$ and city center and central villages $\chi^{2}(\mathrm{sd}=2, \mathrm{n}=39)$ $=8,989, \mathrm{p}<.05$. Other than these, significant differences have not been observed.

\subsection{Findings Related to the Levels of Inter-Organizations Collaboration}

In the following table (Table 11), between educational organizations' inter-organization collaboration levels score and significant difference values corresponding to the administrators' opinions (by LCS) are given.

As shown in the Table 11, the total number of ties in all collaboration levels has been determined as 942 (ties=942). The most collaboration by educational organizations has taken place in the Cooperation level (ties=361). The least collaborated level has been identified as Coalition level (ties=98). According to this, it is understood that a majority of the collaboration carried out by the educational organizations within the network with each other and with other organizations are in the form of helping each other and solidarity. The largest amount of participation in collaboration has been observed in the Coordination level (network size $=60$ ). The least amount of participation (network size $=46$ ) and the least number of collaboration has taken place in the Coalition level.

Table 10. Differences among the Type of Organizations and Physical Distance about the Sharing Building-Places

\begin{tabular}{cccccccc}
\hline Variable & Group & $\mathrm{n}$ & $\begin{array}{c}\text { Average of } \\
\text { Squares }\end{array}$ & sd & $\chi^{2}$ & $p$ & $\begin{array}{c}\text { Significant } \\
\text { Difference }\end{array}$ \\
\hline Organization & Primary school & 22 & 16,41 & 2 & 6,193 & 0,045 & $1-3$ \\
kind & Secondary school & 11 & 22,73 & & & & \\
Affiliated org. & 6 & 28,17 & & & & $1-3$ \\
Physical & Center & 21 & 24,33 & 2 & 8,989 & 0,011 & \\
distance & Vicinity & 9 & 18,72 & & & & \\
& & & & & & & \\
\hline
\end{tabular}

Table 11. Inter-Organizations Collaboration Levels

\begin{tabular}{|c|c|c|c|c|c|}
\hline & Collaboration Levels & Ties & Network Size & Isolated & Significant Difference \\
\hline $2^{\text {nd }}$ Level & Cooperation & 361 & 58 & 10 & -- \\
\hline $3^{\text {rd }}$ Level & Coordination & 167 & 60 & 8 & $\begin{array}{c}\text { Organization size: Between big } \\
\text { schools ( } \mathrm{BS}=400 \text { and over students) } \\
\text { and small schools ( } \mathrm{SS}=99 \text { and less } \\
\text { students). On a higher level in big } \\
\text { schools compared to small schools. }\end{array}$ \\
\hline $5^{\text {th }}$ Level & Collaboration & 162 & 51 & 17 & -- \\
\hline $1^{\text {st }}$ Level & Networking & 154 & 51 & 17 & -- \\
\hline $4^{\text {th }}$ Level & Coalition & 98 & 46 & 22 & $\begin{array}{c}\text { Organization size: Between big } \\
\text { schools ( } \mathrm{BS}=400 \text { and over students) } \\
\text { and small schools ( } \mathrm{SS}=99 \text { and less } \\
\text { students). On a higher level in big } \\
\text { schools compared to small schools. }\end{array}$ \\
\hline TOTAL & & 942 & & & -- \\
\hline
\end{tabular}


Table 12. Differences among the Size of Organizations about the Collaboration Levels

\begin{tabular}{cccccccc}
\hline Variable & Group & $\mathrm{n}$ & $\begin{array}{c}\text { Average of } \\
\text { Squares }\end{array}$ & $\mathrm{sd}$ & $\chi^{2}$ & $p$ & $\begin{array}{c}\text { Significant } \\
\text { Difference }\end{array}$ \\
\hline \multirow{3}{*}{ Coordination } & 99 and less & 11 & 11,55 & 2 & 10,972 & 0,004 & $1-3$ \\
& $100-399$ & 17 & 20,68 & & & & \\
\hline \multirow{3}{*}{ Coalition } & 400 and more & 11 & 27,41 & & & & $1-3$ \\
& 99 and less & 11 & 14,32 & 2 & 9,404 & 0,009 & \\
\hline
\end{tabular}

In the study, it has been analyzed whether the collaboration levels display a significant difference according to the demographic characteristics of the administrators (age, education, duty, experience, administrative experience, duration of employment at the organization, duration of administrative position at the organization) and organizational characteristics (kind, type, size and physical distance). According to the Kruskal Wallis and Mann-Whitney $U$ Test results of the scores of collaboration which has taken place in five different levels of educational organization administrators who have participated in the study, a significant difference has not been observed between the collaboration levels and the demographic characteristics of administrators. A significant difference has been determined only in the coordination and coalition levels according to organization size.

As shown in the Table 12, the Kruskal Wallis test results of the collaboration scores of educational organizations in the collaboration level according to organization characteristics, while there is no significant difference according to institution kind $\chi^{2}(\mathrm{sd}=2, \mathrm{n}=39)=1,010$, $\mathrm{p}>.05$; type $(\mathrm{U}=73,500, \mathrm{p}>.05)$ and physical distance $\chi^{2}(\mathrm{sd}=2, \mathrm{n}=39)=4,266, \mathrm{p}>.05$, There is a significant difference according to organization $\chi^{2}(\mathrm{sd}=2, \mathrm{n}=39)=$ $10,972, \quad \mathrm{p}<.05$. It has been determined that the scores related to the collaboration of big schools in the coordination levels is higher in comparison to small schools (Table 12). According to the Kruskal Wallis Test results of the collaboration scores of the educational organizations in the coalition level, the organizational characteristics of the actors do not display a significant difference according to organization kind, $\chi^{2} \quad(\mathrm{sd}=2, \quad \mathrm{n}=39)=3,499, \quad \mathrm{p}>.05$. Similarly, the results of the analysis also show that there is no difference according to physical distance, $\chi^{2}(\mathrm{sd}=2, \mathrm{n}=39)$ $=2,258, \mathrm{p}>.05$. However, the results of the analysis display that there is a significant difference between small schools and big schools according to organization size in terms of the collaboration of the educational organizations in the coalition level, $\chi^{2}(\mathrm{sd}=2, \quad \mathrm{n}=39)=9,404, \quad \mathrm{p}<.05$.
According to the results of the study, a significant difference existing in coalition in terms of organization size is similar to the coordination level which is defined as a sub-level. According to this, it has been determined that a higher amount of collaboration has been displayed at big schools in comparison to small schools in the coalition level.

\subsection{Findings Related to the Social Network Structural Characteristics of Inter-Organization Collaboration Levels}

In this section in which it is analyzed whether the collaboration relationship levels of educational organizations with other organizations display a difference in accordance with the positions within the social network or not, network structure, centrality measures and structural holes analyses unique to social network analysis have been made use of.

\subsubsection{Findings Related the Network Structure}

According to the social network analysis findings of the study, the total number of actors collaborated with has been determined as 68 (Component=1; Component Size=68). 22 of the 68 actors are primary schools, 11 are secondary schools, 5 are affiliated educational public organizations, 26 are public organizations which are affiliated with various ministries and are not educational institutions, 2 are non-governmental organizations and 1 is a private sector organization. The collaboration network with 68 actors which has been determined in the analyses constitutes a single component. This shows that the collaboration network structure of organizations displays unity and that there is a single component they are all connected with. The collaboration relationships of educational organizations with each other and with other organizations in various levels and areas are quite complex and multi directional according to the social network analysis findings. It has been visually shown in the network map which institutions collaborate with which organizations (Figure 2). 


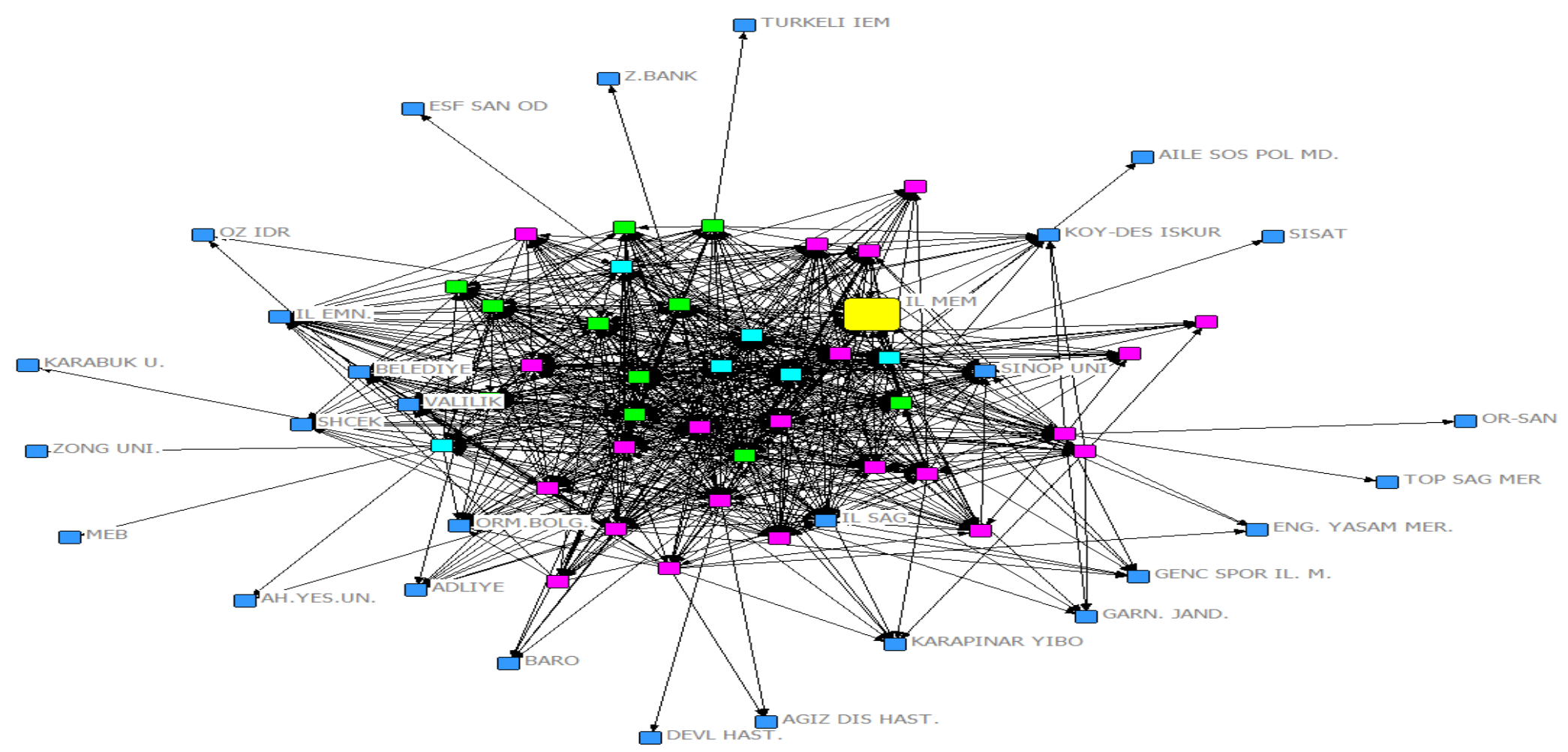

Figure 2. Inter- Organization Collaboration of Educational Networks (All Levels).

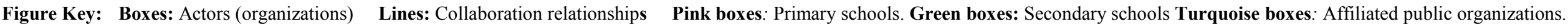
Blue boxes: Other actors (non-educational organization. 
However, educational organizations network characteristic more closed characteristic towards the outside. The connections among the educational organizations are strong but their connections with non-educational organizations are weak. Educational organizations and non-educational organizations within the collaboration network have been visually presented in Figure 3.

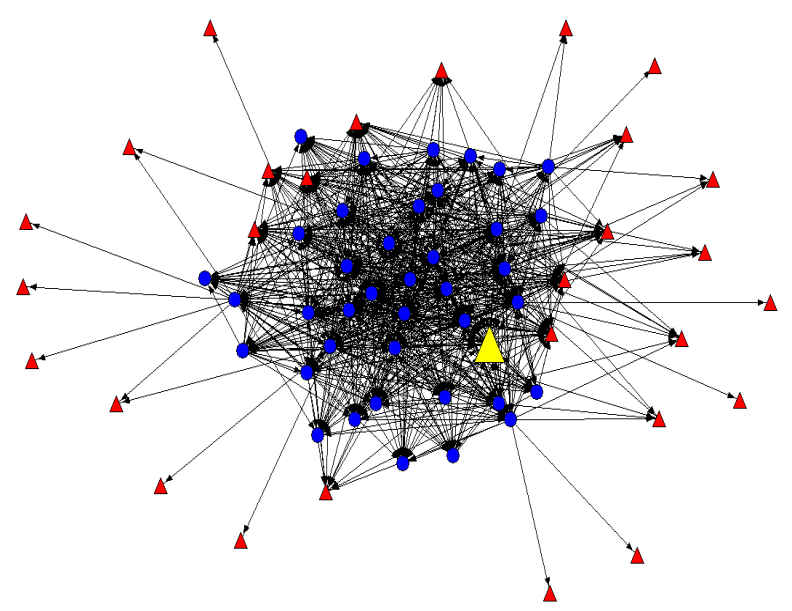

Figure 3. Collaboration Network with Educational Organizations and Non-Educational Organizations.

Figure Key: Yellow and Big Triangle: Provincial Directorate for National Education (PDNE), Circle (Blue): Organizations affiliated with PDNE; Triangle (Red): collaborated with other organizations. Ties: Inter-organizational collaboration relationships at all levels.

As shown in the Figure 3, while educational organizations (blue figures) are located at the center of the network, non-educational organizations (red figures) with fewer connections are located in general around the network. According to this figure, the connections among the educational organizations are strong but their connections with other non-educational organizations are weak. With the purpose of displaying the measurement of this finding visually, density measurement and cluster coefficient analyses are used in the social network technique.

In the study, according to density analysis to $57 \%$ of the maximum possible relationships organizations within the network have been established (Density=0.057). In the cluster coefficient calculation in the network has been determined as 0.520 (coefficient: 0.520 ; weighted coefficient: 0.455). This ratio is interpreted as organizations within the educational organizations collaboration network having connections both inside and outside. The weakness of numerous connections interlocked relatively at the core and the external connections shows that the inner connections of the organizations are stronger in comparison to their external connections. According to the cluster analysis calculation performed with the purpose of determining which organizations are clustered together, the sharp division within the network structure has been found between the two clusters below:

Cluster 1: kur1, kur2, kur3 , kur4 , kur5, kur6 , kur7 , kur8 , kur9 , kur10, kur11, kur13, kur14, kur15, kur16, kur17, kur18, kur19, kur20, kur21, kur22, kur23, kur24, kur25, kur26, kur27, kur28, kur29, kur30, kur31, kur32, kur33, kur34, kur35, kur36, kur37, kur38, kur39, VALILIK (governorship), IMEM (provincial directorate national education), IL SAGLIK MUD (provincial directorate health), SINOP UNI (Sinop university), IL EMNIYET MUD (provincial directorate of security), ORMAN BOLGE MUD (regional directorate of forestry), SHCEK (provincial children), BELEDIYE (municipality), KOY-DES (village project), ISKUR (provincial vocational center).

Cluster 2: kur12, ADLIYE (court), BARO (bar association), GARN. JAND. (military) ,DEVL HAST.,(state hospital) AGIZ DIS HAST. (teeth hospital), ENG. YASAM MER. (disability wellness center), GENC SPOR IL. M. (provincial directorate youth and sport), OR-SAN (company), KARAPINAR YIBO (last year closed a school), TOP SAG MER, (public health service), Z.BANK ( public bank) OZ IDR (public organization), ESF SAN OD (commercial association), TURKELI IEM (another city provincial directorate national education), AH. YES. UN (Ahmet Yesevi university), KARABUK U. (Karabuk university). ZONG UNI, (Zonguldak university), AILE SOS POL MD (provincial directorate family and social politics), SISAT (Sinop commercial association), MEB (Ministry of Education).

There is a significant differentiation between the first and the second clusters $($ Fit $=0.659, \mathrm{r}$-square $=0.116)$. When the two clusters are compared, it can be seen that the first cluster is generally made up of organizations such as educational organizations and the governorship at the city center and provincial directorate for national education, while the second cluster is made up of non-educational organizations with which there is less collaboration.

\subsubsection{Findings Related the Centrality Measures}

In social network analysis, network centrality measurements are used to determine which actors assume more central roles within the network. Network centrality measures are degree centrality, beetweeness centrality, closeness centrality and eigenvector. These calculations which are unique to social network analysis are both calculated for the whole network and presented with descriptive statistics and can be calculated for the actors separately. These measurements in question consist of techniques and analysis units unique to them which display how advantageous roles the actors assumes in a network (Cross and Parker; 2004:192; Scott, 2000:63). In the study, the descriptive statistics calculated for a total of 68 actors which constitute the collaboration network have been presented in Table 13. 
Table 13. Descriptive Statistics of the Educational Organizations Network (Freeman Degree)

\begin{tabular}{cccc}
\hline & Degree & NrmDegree & Share \\
\hline Mean & 21.853 & 32.137 & 0.015 \\
Std. Dev & 15.434 & 22.697 & 0.010 \\
Sum & 1486.000 & 2185.294 & 1.000 \\
Variance & 238.214 & 515.168 & 0.000 \\
Minimum & 1.000 & 1.471 & 0.001 \\
Maximum & 48.000 & 70.588 & 0.032 \\
N of Obs & 68.000 & 68.000 & 68.000 \\
\hline
\end{tabular}

As shown in the Table 13, the lowest degree centrality of the collaboration network constituted by a total of 68 actors has been determined as $1($ Degree $=1)$, the highest degree centrality as 48 (Degree $=48$ ). According to the centrality measurements of the educational organizations collaboration network, the network centrality calculated for the whole network has been determined as $40,21 \%$. According to this, the lowest number of collaboration link has been determined as 1 , the highest number of links as 48 , the average number of links as 21,853 , the ratio of the network being connected to each other as $40,21 \%$. The educational organizations have a higher level of collaboration relationships.

Although an evaluation to be made for the whole network gives a general idea, the calculation of centrality measurements for each ego-network in social network analysis makes it possible to display the situation of the actors of the network within the network[99]. In the study, the results of the collaboration network centrality measurement analysis have been briefly summarized below:

1. In the study, kur10 (Degree $=48)$ has been determined as having the highest degree of the collaboration of the network; thus, it is the actor who has carried out the highest number of collaboration in the network of 68 actors. Kur10 is a primary school at the city center and according to the data obtained from the qualitative dimension of the study, the storage, meeting and conference hall of the school is used by the IMEM (provincial directorate national education). According to this, the organization's having a higher number of facilities allows it to assume a more central role within the collaboration network.

2. In the study, kur37 of the collaboration network has been determined bridge $($ Betw $=249 ; 479)$. Science and Art Center (kur37) which is one of the affiliated institutions has been determined as the institution which has acquired the most benefit from situations in which there were fewer relationships among the other actors or no relationships at all.

3. In the study, kur10 $(C l o=57,500)$ has been determined as the actor with the highest closeness measurement. Closeness which ability to access information within the network and how fast it can connect with the other actors in the network.
4. Eigenvector centrality is an actor's measurement of importance within a network. It defines the relative value of the whole actors in the network. Eigenvector centrality assumes that not all the links are of equal value and that effective actors transmit effectiveness to the less effective actors they are linked with. In the study, kur10 has been determined as the actor with the highest eigenvector centrality of the collaboration network (Eigvec $=0,201)$.

In social network analysis, the actors determined in the measurements in which the network structure involving all of the actors had been identified as the key actors in various areas in terms of the collaboration subjects. Therefore, it has been seen that the analyses are consistent with each other, they point out to the same actors and identified actors come to the fore in analyses performed in terms of the whole collaboration network.

\subsubsection{Findings Related the Structural Holes}

Structural holes show which unconnectedness or disconnectedness situations or links allow the actors within the network to acquire efficiency of present new opportunities [15]. In the calculations related to structural holes, the effective size of each actor's own network, efficiency and constraints within the network are calculated. According to the structural holes analyses obtained in the study, the briefly summarized findings have been reached:

1. The network size shows the total number of other actors (alter) the actor including itself is connected with; in other words, it shows its own individual collaboration network. According to this, the organization with the largest collaboration network has been determined as kur38 (ego-network $=31$ ). kur38 (Guidance Research Center) is an affiliated organization and has a collaboration relationship with the organizations in the whole city in line with its field of work. The two organizations with the smallest network size (kur12, kur13) (ego-network=7) are primary schools and they are both located in the central villages.

2. The number of links shows the number of connections the actors make individually. According to this, the organizations which has collaborated the most has been determined as kur38 (ties $=479$ ). 
Similarly, kur38 which has both the highest number of collaboration and highest number of actors cooperated with is the Guidance Research Center. Kur12 has been identified as the organization with the least number of collaboration ties (ties $=33$ ) and it is one of the primary schools located in the central village.

3. Effective size shows the potential of reaching the other actors according to the number of ties. An actor which has a high effective size can make more use of network opportunities. In the study, the organization with the highest effective size has been determined as kur35 (eff.size $=27,132$ ). Kur35 which is an affiliated public educational organization (Public Education Center) has the most potential to reach other actors and carry out collaboration. Kur4 has been determined as the organization with the lowest effective size (eff.size $=2,636)$. However, this organization was not able to provide data to the study and has been added to the network by the other actors; therefore, it has been evaluated in a one-sided manner. Kur1 has been determined as the organization with the lowest effective size despite the fact that it has contributed to the study (eff.size $=3,882$ ). This organization is a primary school located in the central village.

4. Efficiency shows an actor's (ego) total effect in return for the investment it does on its individual connections. In the study, kur35 has been determined as the organization with the highest efficiency (eff.size $=0,577$ ). According to this, kur35 has a total of $57 \%$ efficiency rate in return for the investment it does to the collaboration network. This ratio shows that it provides a $57 \%$ efficiency rate in return for the unit investment it does to its neighbors (alter) it is connected with. The lowest efficiency rate of the collaboration network belongs to kur4 (eff.size $=$ 0,236 ).

5. Constraint is the measurement of how much an actor is limited (prevented) due to the connections between the other actors. This measurement being low means that the actor is less limited. A high ratio of constraint means that the actor is prevented from benefitting from the collaboration opportunities. In the study, the organization with the lowest constraint has been determined as kur35 (Cons $=0.085)$. Kur35 which Public Education Center is the least limited organization; or in other words, it is the organization whose collaboration opportunities are least limited. Kur7 has been determined as the organization with the highest constraint $($ Cons $=0.145)$. Kur7 is a primary school and is located in the central village.

The structural holes within the network can give individuals or organizations certain positional advantages such as taking the initiative and having control in cases such as information being transmitted or not being transmitted or in controlling the resources[76]. As it can be seen, the constraint rate of organization with high efficiency levels is lower and the constraint rate of organization with low efficiency level are higher. When evaluated in general, the highest efficient usage in the collaboration network belongs to kur35 with $57 \%$ (eff.size $=0.577$; Cons $=0.085$ ). The lowest efficient usage belongs to kur7 with $23 \%$ (eff.size $=$ 0236; Cons $=0.145$ ). Kur35 has an affiliated organization public educational status and is one of the organizations which gives service to all other school and organizations in accordance with its area of expertise. It is located at the city center. Kur7 with low efficiency and high constraint is located in the central village, is quite far from the city center and has a low number of students.

\subsection{Findings Related to the Barriers of Inter-Organization Collaboration}

In this section, participants 36 administrators' opinions of educational organizations about barriers to the collaboration process have been classified as psychological barriers, bureaucratic barriers and barriers arising from the legislation have been presented in Table 14 .

As shown in the Table 14, it has been determined that the greatest barriers to inter-organizational collaboration are caused by bureaucracy. Out of 36 participants, 21 have stated that official correspondence; 17 have stated administrator's extreme dependency on procedures and 8 have the civil servants' not being competent that the greatest barriers to inter-organizational collaboration.

Table 14. According to Educational Administrator's Barriers of the Inter-Organization Collaboration

\begin{tabular}{lc}
\hline Barriers of Inter-Organization Collaboration & $\mathrm{N}$ \\
\hline 1-Psychological barriers & 10 \\
-Negative approach towards collaboration & 6 \\
-Selfishness & 4 \\
-Difference in the status of the organizations & 2 \\
-Reflecting personal problems & \\
2-Bureaucratic barriers & 21 \\
-Official correspondence & 17 \\
-Administrator's extreme dependency on procedures & 8 \\
-The civil servants' not being competent & 8 \\
3-Legislational barriers & \\
\hline
\end{tabular}


According to the participants, appropriate administrator behavior and personal traits towards collaboration either facilitates it or makes it more difficult. In the study, the participants have stated that the problems faced in the collaboration process in general are caused by the behaviors of administrators and their negative approach to collaboration and that administrators who possess communication skills, enterprising, determined, peaceful, solidarity, having occupational knowledge, ability to use technology well, has collaboration culture (open and candid communication, participation and transparency) and believe in collaboration facilitate it. (kur24, kur26, kur32).

Whole group agrees that the old articles of the legislation need to be updated, the needlessly complex legislation should be simplified and some very detailed articles should be regulated as to be left to the responsibility of the administrators and thus, the administrators should be given more job freedom and the way should be cleared to allow them to take initiative. One other obstacle which has been mentioned as arising from the legislation is the prevention of allowing resource exchange between different kinds of organizations and different level schools by the legislation: "...The highest amount of barriers arises from the legislation. We as the high-schools cannot provide resources to primary education. Only organizations with the same status can provide each other with resources. I am not able to do this with my current authority. I need to get permission from the governorship. The legislation allows organizations with the same status to exchange resources." [kur28]. The administrators agree that the real problems are the procedures which cause bureaucracy to operate extremely slowly and those administrators or people who are responsible for the correspondence in the lower levels.

\subsection{Findings Related to the Suggestions to Develop of Inter-Organization Collaboration}

The suggestions made by the participating group in the study on developing collaboration have been grouped under legislation, bureaucracy and operational presented in Table 15.

As shown in the Table 15, although the participants in general have found the legislation satisfactory, they have all suggested that the legislation on school trips should be readjusted and the number of procedures should be reduced $(n=36)$. Among the adjustments by a majority of the participants, reducing the steps and completing the correspondence in a shorter time $(\mathrm{n}=28)$ and providing a work environment of trust which will facilitate the administrators to take initiative can be mentioned.

Table 15. According to Educational Administrator's Suggestions to Develop of the Inter-Organization Collaboration

\begin{tabular}{lc}
\hline SUGGESTIONS & $\mathrm{N}$ \\
\hline 1-Legislational & 36 \\
-Alleviating the regulation of legislation related to school trips & 6 \\
-The opportunity to sign a collaboration protocol between two organizations & 5 \\
-In the legislation which prescribes collaboration with non-educational organizations, & \\
strengthening of the responsibilities of the other organizations (For instance, hiring interns and & 4 \\
students as dictated by the Vocational Training Law No: 3308 and similar laws) & \\
-Updating of the articles of the legislation which are not in line with the conditions of the & \\
present age. & 36 \\
2- Bureaucratic & 28 \\
-Decreasing the number of the procedures. & 8 \\
-Decreasing the steps, preventing correspondence to waste time & 24 \\
-Increasing the authority of the administrators of organizations & 18 \\
3-Operational & 15 \\
- Creating an environment which will allow taking initiatives and the system can be trusted & 8 \\
- Using the state facilities for all organizations & \\
- Making organizations which will bring together the administrators of organizations more & 5 \\
-Creating informative mechanisms on the problems and activities in terms of collaboration and & 4 \\
updating these regularly & 3 \\
-Creating an environment of dialogue & 3 \\
-Making meetings functional & 2 \\
-School administrators having more ideas about the environmental opportunities & \\
-Allocation of budgets to schools in accordance with the number of students & \\
-Announcement of facilities from all organizations' web sites to the other organizations and & \\
the needs & \\
-Organizing more activities which will allow teachers and students to learn about other & 2 \\
organizations & \\
-Discarding practices such approaches as "sitting in the front-at the back at meetings", "I am \\
more important", create a status difference between organizations and make it difficult for \\
school administrators to reach the administrators of organizations. \\
\hline
\end{tabular}




\section{Results and Discussion}

Educational organizations which are an open social system need to keep their connections with their environment firm both to sustain their operations and to make sure that their output complies with the society. Educational organizations carry out numerous collaboration activities with the organizations around them. Various studies show that the collaboration activities which are carried out take place through a wide range of areas and repeated relationships due to the needs of the students. In this study, the findings obtained through three different approaches have verified this as well ([58], [62], [83]). In the study, the collaboration relationship network between the educational organizations at the city center have been analyzed in-depth and the collaboration activities carried out in ten different subjects and the collaboration levels have been analyzed by revealing both the whole network's structural characteristics and the individual network relationships.

According to the social network findings, it has been determined that collaboration has taken place between 68 actors at the city center. Out of 68 actors, 22 are primary schools, 11 are secondary schools, 6 are affiliated public educational organizations, 26 are non-educational public organizations which are affiliated with various ministries, 2 are non-governmental organizations and 1 is a private sector organization. According to each of the three findings obtained in the study through the qualitative, quantitative and social network analysis approaches, the educational organizations have successively collaborated the most with each other and other public organizations and a small amount of private sector and non-governmental organizations. In the study, the areas which the educational administrators collaborate on have been grouped under ten headings in accordance with the grouped subjects headings; sharing buildings-resources, joint projects, social activities, personnel support, sharing financial resources, security, health, sharing information, seminars-courses personnel training support and consulting between administrators. In the study, it has been determined that the most collaboration has been carried out in the subjects of sharing information and consulting between administrators and the least in the subject of joint projects. In this study, the findings obtained have verified this as well ([2], [21], [47], [61], [75]).

The participants of the study have stated that the aspect which most influences the selection of the organization to be collaborated with is the organization having certain facilities and the attitude of the administrators. The characteristics of administrators such as being inclined to collaborate, having a positive view of collaboration and communication show that collaboration is influenced by aspects which are also the basic elements of social relations such as communication, trust, positive collaboration culture. Huxam[46] has stated that in successful collaboration, honesty, candidness, being open hearted, objectivity and truthfulness are the indispensible requirements. Austin[4] has argued that the quality of emotional relationships (positive social relationships) between the key people in carrying out collaboration between organizations greatly influences inter-organizations collaboration. The results obtained in the study are in line with the findings of various studies which show that collaboration is influenced by psychological conditions and operates on the basis of trust.

Due to the hierarchical structure of public schools and the tradition of inter-organizational bureaucracy, the carrying out of orders on collaboration are perceived as duties. Coordination, which is one of the different kinds of collaboration among organization in which hierarchical relationships are established is mandatory. Therefore, establishing coordination requires being informed about one another and carrying out the given tasks in a harmonious manner with the other organizations [45]. In the study, the differentiation of voluntary and mandatory collaboration [85] has not been embraced by the participants. They have perceived mandatory collaboration as carrying out duties. It has been observed in general that the hierarchical level of the organization to be collaborated with is determinant in the perception of voluntariness and mandatories. A majority of the participants have stated that they collaborate with the higher organizations in mandatory manner and both in a voluntary and mandatory manner with the equivalent organizations.

According to the social network findings, the organizations within the educational organizations collaboration network have connections both from the inside and the outside of the network. Educational organizations have numerous connections and are in a high number of collaboration relationships in terms of their collaboration connections with each other and other organizations. It has been observed that the connections of educational organizations with each other are firmer and that they are looser with the other organizations. Their connections with other organizations being relatively less in number/looser can be interpreted as educational organizations network partially reflecting the closure property and display a tighter characteristic inside and a more closed characteristic towards the outside. As for clusters, two clusters have been identified within the network. When the two clusters are compared, it can be seen that the first cluster is generally made up of organizations such as educational organizations and the Governorship at the city center and Provincial Directorate for National Education, while the second cluster is made up of non-educational organizations with which there is less collaboration. The educational organizations having less and remote or loose connections with other organizations which are non-educational organizations while they have close and firm connections among each other is evaluated in different manner in strong links, the power of weak links and structural holes theories. While in strong links theory it is argued that close and firm connections (social relationships) have a higher chance of creating social capital [56]; the power of weak links theory finds remote connections more valuable since there are is a higher chance they transmit 
new information more[22]. As a matter of fact, there is a general acceptance that organizations should have both kinds of connections[67]. In the study, it has been determined that although educational organizations have extremely firm and close connections with the other educational organizations, their external or remote connections are less in number and thus, display a closed image. An image which is firm on the inside and closed to the outside can prevent in particular speedy adaptation to the environment and make it difficult to carry innovations to schools. Especially for organizations such as educational organizations which should meet the needs of all the parts of the society and act as pioneers, this can create a big disadvantage.

According to the findings of the study, the existence of resources which organizations can share allows them to be preferred. Ash[2] in his study has determined that the inner characteristics of organizations with which successful and unsuccessful collaboration is carried out are explicitly different from each other; successful collaboration involve a higher amount of resource dependency, their representatives know each other for longer times, more similar influences, more official/shaped relationships and efficiency perceived at a higher level. According to the findings of the study, the positions of organizations within the social network create a difference in terms of collaboration subjects and levels. In the study, it has been determined that the resources owned by the educational organizations make them preferable in terms of collaboration. When collaboration in the subject of sharing buildings-places and financial resources was taken into consideration, it has been determined that the organizations identified as key actors within the network (kur10, kur35, kur37) are organizations with certain resources (gym, storage, materials) and significantly display a difference. The findings of the study show that collaboration in the subject of sharing buildings-places also display a significant difference in terms of the organization kind and physical distance sub-categories. According to the findings of the study, organizations which assume key roles within the network for each collaboration subject vary. This verifies Lin's [100] argument that relationships which create social capital change in accordance with the purpose of the organization.

The most collaboration carried out by the educational organizations has taken place in the Cooperation Level. The least collaborated level has been determined to be Coalition. According to this, it is understood that the majority of the collaboration carried out by the educational organizations within the network with each other and other organizations has the purpose of helping each other and solidarity. The most participated collaboration has taken place in the Coordination Level. The organizations analyzed in the study being public schools and the hierarchical connections between them can explain the fact that collaboration in the Coordination Level is the most participated collaboration. Despite this, the most collaborated level being Cooperation shows that Cooperation is carried out on the basis of solidarity and helping one another despite the fact that they are public organizations and they are forced to collaborate. At the same time, the network having strong ties in itself and close and firm relationships is in line with the most collaborated level being the level of solidarity and helping one another.

When the ego-networks (individual networks) of the actors within the network were analyzed, two types of evaluations have been done as between the whole education network and between only actors which are educational organizations. In the analyses done for the whole network, kur10 has been determined as the organization with the highest degree, therefore the actor which has carried out the highest number of collaboration. The same actor has also been determined as the actor who most speedily connected with the actors due to its ability to access information and as a relatively more efficient and important actor compared to the other actors in the whole network. The high number of resources owned by the organization, its being very close to the center of the city and being very close physically to the Provincial Directorate for National Education (actor: IMEM) are its specific characteristics. In an evaluation done only on the educational organizations within the network, the Guidance Research Center (kur38) has been determined as the organization with the biggest collaboration network. It has a collaboration relationship with all the educational organizations in the city. Similarly, the organization with the highest number of collaboration has been determined as the same center. The efficiency of affiliated public educational organizations within the network has been determined to be higher compared to the schools in general. This becomes more apparent in the evaluation made only in terms of the educational organizations. The organization with the highest constraints is a primary school located in one of the central villages. In general, the level of efficiency in the schools in villages and those which are far from the city center has been determined to be low. Being far from the center of the city creates a constraint in terms of accessing the resources and the links.

\section{Suggestions}

In the study, suggestions of the educational administrators on developing inter-organizations collaboration have been received as well. These suggestions have been presented in a detailed manner under the findings heading. To briefly summarize, the administrators underlined improving communication between administrators, developing dialogues and removing the barriers arising from the legislation and operation which prevent the use of facilities owned by organizations by all of the other organizations the most in their suggestions on the legislation, bureaucracy and facilitation of operations. In particular, the road should be pawed for school administrators to be able to give their own momentary 
decisions and take initiative in establishing collaboration with other organizations and the necessary readjustments should be done for this. Besides these, the study has three basic suggestions:

1. Firstly, educational organizations need to increase their collaboration links not only with the other educational organizations, but with the other organizations which are non-educational. Although their image that is closed to the outside increases solidarity among themselves, this will make it more difficult for them to access resources outside of schools and to adapt themselves to the changing and developing environment.

2. The gains to be acquired by collaboration between schools are not only limited with sharing resources. Atkinson, Springate, Johnson and Halsey[3] have shown that collaboration which takes place between schools can also assume a function in the integration of social culture. It is apparent that the affiliated public educational organizations within the collaboration network will play an efficient role in this. It has been seen that affiliated public educational organizations such as Public Education Center, Guidance Research Center and Vocational Training Center have assumed efficient roles within the whole network. For these organizations to be used in a more efficient manner, it is necessary to support them with expert personnel.

3. The more frequent use of social network analysis in educational researches can provide new perspectives for data collected in the studies. The repetition of similar studies to this one for different cities will also allow for the comparison of collaboration links of schools in the city level.

\section{Note}

*The abstract of this paper was presented at 2nd International Conference on Lifelong Learning and Leadership for All (ICLEL-16), in Liepaja on July, 21-23, 2016.

\section{REFERENCES}

[1] Acar, M. (2004), Örgüsel Yönetim. Ankara: Nobel Yayınevi.

[2] Ash, A.M. (1989) Interorganizational relations and effectiveness in school-business partnerships. Dissertations from ProQuest. Paper: 2796.

http://scholarlyrepository.miami.edu/dissertations/2796

[3] Atkinson, M., Springate, I., Johnson, F. \& Halsey, K. (2007). Inter-school collaboration: a literature review. Slough: NFER

[4] Austin, J. E. (2000) Strategic Collaboration Between Nonprofits and Business. Nonprofit and Voluntary Sector Quarterly. 29 (1), 69-97.
[5] Balcı, A. (2009). Sosyal Bilimlerde Araştırma Yöntem, Teknik ve İlkeler. Ankara: Pegem Akademi.

[6] Barabasi, A.L. (2010) Bağlantılar. İstanbul: Optimist Yayınlar1.

[7] Barringer, B. R. \& Harrison, S. (2000). Walking a Tighrope: Creating Through Interorganizational Relationship. Journal of Management..26 (3), 367-403.

[8] Berkowitz, S.D. (1988) Afterword: Toward a Formal Structural Sociology. In B. Wellman and S.D. Berkowitz (Eds.), Social Structures, A Network Approach (pp. 447-497) London: Jai Press.

[9] Bolat, S. (1995) Eğitim Örgütlerinde İșbirliği (Hacettepe Üniversitesi Örneği).Yayınlanmamış Doktora Tezi, Hacettepe Üniversitesi Sosyal Bilimler Enstitüsü, Ankara.

[10] Borgatti, S.P.,\& Foster, P.B. (2003). The Network Paradigm in Organizational Research: A review and Typology. Journal of Management. 29(6), 991-1013.

[11] Borgatti, S.P.; Everett, M.G. \& Freeman, 1.c. (2002) UCINET for Windows, Version 6.59: Software for Social Network Analysis. Harvard, MA: Analytic Technologies.

[12] Borden, L.M. \& Perkins, D.F. (1999) Assessing Your Collaboration: A Self Evaluation Tool. http://www.joe.org/joe/1999april/tt1.php/The (online).

[13] Bourdieu, P. (1983) Forms of Capital. Handbook of Theory and Research For the Sociology of Education. 241-258.

[14] Burt, R.S. (1992) Structural Holes: The Social Structure of Competition. Cambridge, MA: Harvard University Press.

[15] Carrington, P.J. ; Scott, J. \& Wassserman, S. (2005) Models and Methods in Social Network Analysis in the Social Sciences. NY: Cambridge University Press

[16] Coburn, C. E., Russell, J.L.; Kaufman, J.H. \& Stein.M.K. (2012) Supporting Sustainability: Teachers' Advice Networks and Ambitious Instructional Reform." American Journal of Education 119 (1): 137-82.

[17] Conery, M.J. (2012) Mapping The Terrain: A Social Network Analysis Of Elementary Teachers' Perceptions Of Social Leadership Practice. Dissertations 3548511, ProQuest, Northern Arizona University.

[18] Creswell, J.W. (2009). Research Design: Qualitative, Quantitative, and Mixed Methods Approaches. London: SAGE Publications. 3rd.edt.

[19] Creswell, J.W. (2012) Educational Research: Planning, Conducting, And Evaluating Quantitative And Qualitative Research. Boston: Pearson Education, Inc.

[20] Cross, R. \& Parker, A. (2004) Sosyal Şebekelerin Saklı Gücü. İstanbul: Henkel Yayıncılık.

[21] Cross, J.E. , Dickman, E. , Newman-Gonchar, R. \& Fagan, J.M. (2009) Using Mixed-Method Design and Network Analysis to Measure Development of Interagency Collaboration. American Journal of Evaluation (30) 310-329.

[22] Csermely; P. (2006) Weak Links: Stabilizers of Complex Systems from Proteins to Social Networks With 52 Figures and 12 Tables 123. Germany: Springer.

[23] Daly, A.J. (2010) Social Network Theory and Educational 
Change. Harvard Education Press.

[24] Daly, A. (2012) Data, Dyads and Dynamics: Exploring Data and Social Networks in Educational Improvement. Teachers College Record. 114(11)1-38.

[25] Datnow, A.(2012) Teacher Agency in Educational Reform: Lessons from Social Networks Research. American Journal of Education 119 (1): 193-201.

[26] Degenne, A. \& Forse, M. (1999) Introducing Social Networks. CA: Sage

[27] Dulupçu, M.A. \&Sungur, O. (2007) Yenilik, İşbirliği ve Girişimcilik: Batı Akdeniz Bölgesi KOBİ'lerinin Tutumlarının Değerlendirilmesi. Ankara: KOSGEB.

[28] El Ansari, W., \& Weiss, E. S. (2006). Quality of research on community partnerships: Developing the evidence base. Health Education Research, 21,75-180.

[29] Emirbayer, M. \& Goodwin, J. (1994) Network Analysis, Culture, Problem of Agency. The American Journal of Sociology. 99 (6) 1411-1454.

[30] Finnigan, K S.,\& Daly, A.J. ( 2012). Mind the Gap: Organizational Learning and Improvement in an Underperforming Urban System. American Journal of Education 119 (1): 41-71

[31] Frey, B. Lohmeier,J.H.; Lee, S.W. \& Tollefson, N. (2006) Measuring Collaboration Among Grant Partners. American Journal of Evaluation. 27, 383-392.

[32] Freeman, L.C. (2004) The Development of Social Network Analysis: A Study In The Sociology Of Science. Vancouver : $\Sigma$ P Empirical Press.

[33] Gajda, R. (2004) Utilizing Collaboration Theory to Evaluate Strategic Alliances. American Journal of Evaluation. 25,65-77.

[34] Gajda, R. \& Koliba, c. (2007) Evaluating the Imperative of Interorganizational Collaboration. American Journal of Evaluation. 28,26-44.

[35] Gargiulo, M. \& Benassi, M. (2000) Traped in Your Own Net? Network Cohesion, Structural Holes and Adaption of Social Capital. Organization Science. 11 (2) 183-196.

[36] Glesne, C. (2013) Nitel Araştırmaya Giriş. Ankara: Anı Yayınc1lik.

[37] Granovetter, M. (1982) The Strength of Weak Ties: A Network Theory Revised. In P.V. Marsden and N. Lin (Eds.), Social Structure and Network Analysis ( pp. 105-130). C.A.: Sage Publications.

[38] Granovetter, M. (1985) Economic Action and Social Structure: The Problem of Embeddedness. American Journal of Sociology. 91(3), 481-510.

[39] Gray, B. (1989). Collaborating: Finding Common Ground For Multiparty Problems. San Francisco: Jossey-Bass.

[40] Gulati, R. (1998) Aliances and Network. Strategic Management Journal, 19, 293-317.

[41] Hanneman, R. A., \& Riddle, M. (2005). Introduction to Social Network Methods. http://faculty.ucr.edu/ hanneman/nettext/(Online).
[42] Hanneman, R. (1987) Computer-assisted Theory Building. CA: Sage.

[43] Himmelman, A.T. 2002. Collaboration for a Change: Definitions, Decision-Making Roles, and Collaboration Process Guide, Minneapolis: Himmelman Consulting.

[44] Hogue, T. ( 1994) Community Based CollaborationsWellness Multiplied. Oregon Center for Community Leadership.

http://crs.uvm.edu/nnco/collab/framework.html\#framework (online)

[45] Hoy, W. \& Miskel, C.G. (2010). Eğitim Yönetimi: Teori, Araştırma ve Uygulama. Ankara: Nobel Yayın Dağıtım.

[46] Huxam, C. (2003) Theorizing Collaboration Practice. Public Management Review, 5 (3) 401-423.

[47] Jager, K. (2005) School Collaboration. Education Improvement Partnerships, East Basildon Local Delivery. http://www.slideshare.net/Annie05/school-collaboration-pres entation 1.1.2011 tarihinde erişildi.

[48] Kadushin, C., Lindholm, M., Ryan, D., Brodsky, A. \& Saxe, L. (2005). Why It Is So Difficult to Form Effective Community Coalitions. City \& Community, (4) 255-275.

[49] Kaya, Y. (2005) Değişen Yapılarda İşbirliği ve Çatışma. İstanbul Üniversitesi Sosyoloji Konferansları Dergisi. 31, 161-175.

[50] Keast,R.B. \& Mandall, M (2009) What is Collaboration? Australian Research Alliance for Children and Youth. ARACY. Advanced Collaboration Practice. http://www.workforce.org.au/media/59204/resourcing_colla boration_what_is_collaboration_factsheet1.pdf(online).

[51] Keast, R.B. \& Mandall, M (2007) Getting the Right Mix: Unpacking Integration Meanings And Strategies. International Public Management Journal. 10(1) 9-33.

[52] Kensler, L. A. W (2012). Review of Social Network Theory and Educational Change, by Alan J. Daly. American Journal of Education 119 (1): 203-07.

[53] Kessler, G. (1985) Sosyolojiye Başlangıç. İstanbul: İstanbul Üniversitesi İşletme Fakültesi Yayınları.

[54] Kinduff, M. \& Tsai, W. (2007) Social Networks and Organizations. London: SAGE Publications.

[55] Knoke, D. \& Kublinski, J.H. (1982) Network Analysis. Beverly Hills: Sage Publications.

[56] Krachardt, D. (1992). The Strength of Strong Ties: The Importance of Philos in Organizations. In N. Nohria and R. Eccles (Eds.), Networks and Organizations: Structure, Form and Action. Boston: Harvard University School Press.

[57] Leana, R.C. \& Buren, V.H.J. (1999) Organizational Social Capital and Employment Practices. Academy of Management Review. 24(3) 538-555.

[58] Lieberman, A. \& Grolnick, M. (1996) Networks and reform in American Education. Teacher College Record. 98(1) 8-45.

[59] Marsden, P.V. (2005) Recent Developments in Network Measurement Models and Methods in Social Network Analysis. In P.J. Carrington, J. Scott and S. Wasserman. Models and Methods in Social Network Analysis (pp. 8-30). New York: Cambridge University Pres. 
[60] McCarty, C. \& Bernard, H.R. (2003) Social Network Anaysis. In K.Christensen and D. Levinson (Eds.), The Encyclopedia of Community: From the Village to the Virtual World. (pp. 1321-1325). CA: Sage Pub.

[61] McDonald, J. \& Klein, E.J. (2003) Networking For Teacher Learning: Toward A Theory of Effective Design. Teacher College Record. 105(8), 1606-1601.

[62] Marra, R.M.; Peterson, K. \& Britsch, B. (2009) Collaboration As a Means To Building Capacity: Results and Future Directions of the National Girls Collaborative Project. American Educational Researchers Association (AERA), 13 - 17 April, 2009, San Diego.

[63] Miles, M. B. \& Huberman, A. M. (1994). Qualitative Data Analysis: An Expanded Sourcebook. C.A: SAGE Publications.

[64] Moolenaar, N.M. (2012) A Social Network Perspective on Teacher Collaboration in Schools: Theory, Methodology and Applications. American Journal of Education. 119, 7-39.

[65] Moreno, J. L. (1963) Who Shall Survive. İstanbul: İstanbul Matbaasi.

[66] Oliver, C. (1990) Determinants of Interorganizational Relationships: Integration and Future Directions. Academy of Management Review. 15(2)241-265.

[67] Öztaş, N. (2007). Sosyal Sermayenin Ağbağ Kuram(ları): Dayanışmacı ve Aracı Sosyal Sermaye. Ankara: Amme İdaresi Dergisi, 40 (3) 79-98.

[68] Öztaş, N. \& Acar, M. (2004). Ağbağ Analizine Giriş: Kavramlar ve Yöntemler. İçinde M. Acar ve H. Özgür. (Eds.), Çağdaş Kamu Yönetimi II. (s.s. 288-316). Ankara: Nobel Yayınevi.

[69] Packdell, A.A. (2009) Interorganizational Collaboration: An Exploratory Study of Collaborative Relationships within a Statewide Leadership Project. Dissertation ProQuest LLC. 3442073

[70] Podolny, J. \& Page, K. (1998) Networks Forms of Organizations. Annual Review of Sociology. 24,57-76.

[71] Putnam, L. \& Jablin, (2012) F. Emergence of Communication Networks. In P.R Monge \& N.S. Contractor (Eds.), New Handbook Of Organizational Communication. Newbury Park http://hyperion.math.upatras.gr/commorg/nosh/HOCNets.ht $\mathrm{ml}$

[72] Scott, J. (2000) Social Network Analysis: A Handbook. London: Sage

[73] Sennett, R. (2012). Beraber. İstanbul: Ayrıntı Yayınları.

[74] Shah, H. \& Shaikh, F. (2011) Globalization and Recent Trends in Corporate Governance and Strategic Management. Journal of Business Strategies (1993-5765) June, 5(1) 32-38.

[75] Slater, J. J. \& Ravid, R. (2010). Collaboration in Education. N.Y: Routledge.

[76] Sözen, C.H. \& Gürbüz, S. (2012) Örgütsel Ağlar. İçinde H.C. Sözen VE H.N. Basım (Eds.) Örgüt Kuramları (s.s. 301-326) İstanbul: Beta Basim.

[77] Spillane, J., \& Kim, C.M. (2012). An Exploratory Analysis of Formal School Leaders' Positioning in Instructional Advice and Information Networks in Elementary Schools. American
Journal of Education 119 (1): 73-102.

[78] Tavşancıl, E. (2006). Tutumların Ölçülmesi ve SPSS ile Veri Analizi. Ankara: Nobel Yayınları.

[79] Taymaz, H. (2007) Okul Yönetimi. Ankara: PegemA Yayıncılık (8. Baskı).

[80] Titrek, O \& Celik, O. (2011) Relations between Self-Awareness and Transformational Leadership Skills of School Managers. New Educational Rewiew. Vol. 23 ,pp. 355-369-369.

[81] Toytok, E.H; Korkmaz, M. \& Anik, S. ( 2016) Environmental Conditions of the City in which Teachers Serve and their Organizational Commitment Perception Levels. Anthropologist, 24(1): 90-96.

[82] Van De Ven, H.A. (1976) On the Nature, Formation and Maintenance of Relations Among Organizations. Academy of Management Review,1(4)24-36.

[83] Varga-Atkins, T. ; O’Brien, M; Burton, D. ; Campbell, A. \& Qualter, A. (2010) The Importance of Interplay Between School-Based and Networked Professional Development: School Professionals' Experiences of Inter-School Collaborations in Learning Networks. Journal of Education Change. (11) 241-272.

[84] Wasserman, S.,\& Faust, K. (1994). Social Network Analysis: Methods and Applications. New York: Cambridge University Press.

[85] Whetten, D.A. (1981) Interorganizational Relations: A Rewiew of the Field. Journal of Higher Education. 52 (1) $1-28$.

[86] Woodland, R.H \& Hutton, M. S ( 2012) Evaluating Organizational Collaborations : Suggested Entry Points and Strategies. American Journal of Evaluation (33) 366-383.

[87] Chrislip, D. \& Larson, C. (1994). Collaborative leadership, San Francisco: Jossey-Bass.

[88] Peterson, N. L. (1991). Interagency collaboration under Part $\mathrm{H}$ : The key to comprehensive, multidisciplinary, coor-dinated infant/toddler intervention services. Journal of Early Intervention, 15(1), 89-105.

[89] Beckert, Jens. "Economic Sociology and Embeddedness: How Shall We Conceptualize Economic Action?" Journal of Economic Issues37, 3 (2003): 769-788.

[90] Uzzi, Brian. "Embeddedness and the Making of Financial Capital: How Social Relations and Networks Benefit Firms Seeking Financing” American Sociological Review. 1999, 64, pp. 481-505.

[91] Tsai, W., \& Ghoshal, S. (1998). Social capital and value creation: The role of intrafirm networks. Academy of Management Journal, 41(4), 464-476.

[92] Coleman, J. 1988. "Social Capital in the Creation of Human Capital." American Journal of Sociology 94:S95-121

[93] Lin, N. (2001). Building a network theory of social capital. In Lin, N., Cook, K., \& Burt, R. (Eds.), Social Capital Theory and Research (pp. 3 - 30). New Brunswick, NJ: Transaction Publishers.

[94] Pounder, D. G. (1998). Restructuring schools for collaboration: Promises and pitfalls. Albany, NY: State University of New York Press. 
[95] Hanford, S., Houck, J., Iler, E. and Morgan, P. (1997). Public and Private School Collaborations: Educational Bridges into the 21 st Century. The Forum for Public/Private Collaboration. Teachers College, Columbia University.

[96] Deal, T., Purinton, T., \& Waetjen, D. C. (2008). Making sense of social networks in schools. Thousand Oaks, CA: Corwin Press.

[97] Moolenaar, N. M., \& Daly, A. J. (2012). Social networks in education: Exploring the social side ofthe reform equation.American Journal of Education, 119(1),1-6.

[98] Resnick, L. B.,\& Scherrer, J. (2012). Social networks in
"Nested Learning Organizations." American Journal of Education, 119(1), 183-192.

[99] Everett, M. and Borgatti, S. P. (2005). Ego network betweenness. Social Networks 27. 31-38.

[100] Lin, N. (2000). Inequality in social capital. Contemporary Sociology, 29(6), $785-795$.

[101] Thorelli, H.B. ( 1986) Networks : Between markets and hierarchies. Strategic Management Journal. 7, 37-51.

[102] Parkhe, A. ; Wasserman, S. \& Ralston, A.D. (2006) New Frontiers in network development. Academy of Management Review, 31 (3), 560-568. 